\title{
APN Science Bulletin
}

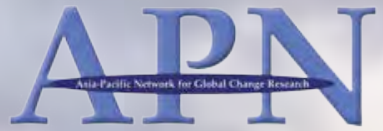

Deploying Internet-Based MRV Tools and

Linking Ground-Based Measurements with Remote Sensing for Reporting Forest Carbon

Assessing Potential Co-Benefits of REDD+ in Shifting Cultivation Landscape

Capacity Building of ALOS Satellite Data to Support Mapping and Monitoring Deforestation and Degradation in Thdonesia

Participatory Approaches to Forest Carbon Accounting to Mitigate Climate Change, Conserve Biodiversity and Promote Sustainable Development

Assessment and Promotion of Strategies and Techniques for the Reuse of Agricultural Straw Residues in China
Advancing Local Green Practices Towards Establishing Sound Material Gycle Society in Asian Cities

Towards Low Carbon Development and Transition in Asia

Future Earth in Asia and the Pacific

International Conference on Climate Change Impacts and Adaption for Food and Environmental Security

Science-Policy Dialogue on Challenges of Global Environmental Change in Southeast Asia

Building Resilience with Common Capital

APN-IGES-Hyogo Symposium on Low Carbon Society in Asia through Dissemination of Renewable Energy. Technology 
Scientific Planning Group Executive Editors:

Dr. Alexander Sterin, SPG Member for Russian Federation and SPG Co-Chair

Dr. Luis Tupas, SPG Member for the United States of America and SPG Co-Chair

\section{Managing Editor:}

Dr. Linda Anne Stevenson, Division Head, Communication and Scientific Affairs, APN Secretariat

Citation: Stevenson, L. A., Sterin, A., \& Tupas, L. (Eds.). (2013). APN Science Bulletin (Issue 3 Supplement). Asia-Pacific Network for Global Change Research. ISSN 2185-761X.

Design and layout: Christmas de Guzman/APN

Cover images: Seth Vidal (front); Taniya Koswatta/APN (back)

(C) 2013 Asia-Pacific Network for Global Change Research (APN) 


\section{PREFACE}

The APN's activities continue to grow and this has warranted a supplement to Issue 3 of our Science Bulletin. The supplement showcases 12 activities that were conducted in 2012 and early 2013 that sit outside the APN's core programmes of activities, the ARCP and CAPaBLE Programmes.

Showcasing articles from two focused activities that began in 2010 with funding from the Ministry of the Environment, Japan, the supplement reports two featured projects from the Ecosystems, Biodiversity and Land Use (EBLU) scientific focus; and two from Resources Utilisation and Pathways for Sustainable Development (RUSD). The articles highlight issues such as solid waste management, emerging work on biochar development and the UNFCCC-driven REDD+ and MRV system and their importance for sustaining healthy forest ecosystems in Southeast Asia.

Six articles present a range of activities approved by the APN's governing body, the Inter-Governmental Meeting (IGM).These activities ensure that APN's work goes beyond its scientific focus and encompasses its other broad objectives of collaboration and networking, facilitating science and policy interactions, and raising awareness on issues of importance under the global change umbrella. Most of the activities presented in this supplement were jointly organised by the APN and other key institutions and organisations and, in essence, highlight the broader nature of APN's work. Noteworthy in the present supplement are the outcomes of a workshop on Future Earth, a new 10-year Earth system sustainability programme, which features the key important activities for Future Earth at the regional level in Asia and the Pacific. Two other activities, the Low Carbon Symposium and the Sub-regional Science-Policy Dialogue, also highlight science-policy and awareness-raising activities at the local and regional levels - the latter, which was held in Southeast Asia in mid-2012, delivered key outputs from the APN in collaboration with START. 


\section{CONTENTS}

I Preface

3 Focused Activities:

Ecosystems, Biodiversity and Land Use (EBLU)

$4 \quad$ Deploying Internet-Based MRV Tools and Linking Ground-Based Measurements with Remote Sensing for Reporting Forest Carbon

10 Assessing Potential Co-Benefits of REDD+ in Shifting Cultivation Landscape

13 Capacity Building of ALOS Satellite Data to Support Mapping and Monitoring Deforestation and Degradation in Indonesia

\section{EBLU2010-03NMY(R)-SCHEYVENS}

17 Participatory Approaches to Forest Carbon Accounting to Mitigate Climate Change, Conserve Biodiversity and Promote Sustainable Development

21 Focused Activities:

Resources Utilisation and Pathways for Sustainable Development

22 Assessment and Promotion of Strategies and Techniques for the Reuse of Agricultural Straw Residues in China
RUSD2011-02CMY(R)-SURJAN

Advancing Local Green Practices Towards Establishing Sound Material Cycle Society in Asian Cities

29 AOA Projects:

Other Activities Endorsed by the Inter-Governmental Meeting (IGM)

30 Towards Low Carbon Development and Transition in Asia

34 Future Earth in Asia and the Pacific

39 International Conference on Climate Change Impacts and Adaption for Food and Environmental Security

43 Science-Policy Dialogue on Challenges of Global Environmental Change in Southeast Asia

47 Building Resilience with Common Capital

51 APN-IGES-Hyogo Symposium on Low Carbon Society in Asia through Dissemination of Renewable Energy Technology 


\section{EBLU \\ PROJECTS}

Focused Activities:

\section{Ecosystems, Biodiversity and Land Use (EBLU)}




\title{
Deploying Internet-Based MRV Tools and Linking Ground-Based Measurements with Remote Sensing for Reporting Forest Carbon
}

\author{
Jay H. Samek', David L. Skole, Sithong Thongmanivong, Do Xuan Lan, Phung Van Khoa \\ 'Corresponding Author \\ Michigan State University, USA \\ Email: samekjay@msu.edu
}

ABSTRACT: This research demonstrates (1) an Internet-based forest carbon measurement system to support Tier 3 level carbon stock assessments; and (2) a method that links ground-based measurements or IPCC Tier 1 biomass values with Earth Observation satellite remote sensing to map carbon across large areas at Landsat-class (15-metre) spatial resolution. We demonstrated web-based tools and carbon mapping methods in two case study areas: Sangthong District, Lao PDR and Bac Kan Province, Viet Nam. Results for carbon stock in the forest strata for these two pilot areas are reported via an online system using geographic parcels and plot information, and tree inventory data collected at the plot level. The carbon mapping method utilises a vegetation continuous fields (VCF) algorithm, which is used to downscale IPCC Tier 1 default biomass values or stratified Tier 3 biomass values to compute carbon at 15-metre Landsat pixel resolution. The Internet-based forest carbon system and mapping method is a globally-deployable, scalable MRV (measurement, reporting and verification) system that is cost-effective and uses rigorous scientifically-valid methods for calculating carbon. The system is online at http://mrv.carbon2markets.org.

KEYWORDS: forest carbon, REDD+, MRV tools, satellite remote sensing 


\section{Introduction}

Forests play a critical role in mitigating climate change through the sequestration and storage of carbon in perennial woody biomass and soils. The Intergovernmental Panel on Climate Change (IPCC) reported in 2007 that about one third of anthropogenic emissions of atmospheric $\mathrm{CO}_{2}$ since 1750 are from land-use changes, primarily from deforestation and about 20\% are from land-use changes for the 1990s (IPCC, 2007). Recent estimates derived from satellite remote sensing conclude that deforestation and forest degradation accounted for 7-14\% of global anthropogenic $\mathrm{CO}_{2}$ emissions for the period 2000 to 2005 , with $32 \%$ of deforestation emissions coming from South and Southeast Asia (Harris et al., 2012).

Extremely large financial investments are now being made in forestry and agriculture carbon projects for climate mitigation in developing countries (e.g. the Climate Investment Fund-Forest Investment Program, the World Bank - Carbon Partnership Facility). While these large investments in forest and agriculture carbon initiatives are moving ahead rapidly in response to international climate policy, the basic framework for measurement and verification is almost non-existent. There is a desperate need for rapid development of proofs of concepts for what the international community calls MRV systems (monitoring, reporting and verification systems). A recent report from the World Economic Forum's Task Force on Low Carbon Prosperity has put it this way: "To develop the necessary level of sophistication of systems required for accurate REDD+ monitoring, reporting and verification, a major publicprivate initiative is required to develop comprehensive Earth Observation systems and field measurement and monitoring systems to be ready for use by 1 January 2013" (Agrawala et al., 2009).

Implementing forest carbon emission reduction and sequestration projects must show that carbon mitigation is real and permanent and do so in a cost-effective manner. Accurate measurement and

\section{HIGHLIGHTS}

» Development of online MRV tools for Tier 3 forest carbon stock measurement reporting (mrv.carbon2markets.org)

» Tier 3 carbon stock estimates for Sangthong District, Lao PDR deciduous forest and two community forests in $\mathrm{Na} \mathrm{Ri}$ District, Bac Kan Province,Viet Nam

» Tier I carbon stock estimates integrating IPPC default values with Earth Observation remote sensing analysis methods for Bac Kan Province, Viet Nam

» Tier 3 carbon stock estimates integrating ground-based data with Earth Observation remote sensing analysis methods for Bac Kan Province, Viet Nam

» REDD+ forest carbon stock measurements and emissions reporting capabilities (through Internet-based tools and services) support robust scientific methods and transparency

monitoring of carbon stock changes in biomass must use robust scientific methods. Reporting and verification procedures must follow accepted protocols. Combined, these form the elements of an MRV system. Carbon compliance regulatory regimes, multilateral investment programmes, national reporting schemes and carbon markets will need robust, cost-effective systems for measuring, reporting and verification. This research demonstrates (1) an Internet-based forest carbon measurement system to support Tier 3 level carbon stock assessments; and (2) a method that links ground-based measurements or IPCC Tier 1 biomass values with Earth Observation satellite remote sensing analysis to map carbon across large areas at Landsat-class (15-metre) spatial resolution. We have developed a globally-deployable, scalable MRV system that is cost-effective and rigorous and have demonstrated its functionality with pilot activities in Lao PDR and Viet Nam.

\section{Methods and Results}

\section{Pilot Project Areas}

The two pilot areas ${ }^{1}$ selected for the research project were Sangthong District,

\footnotetext{
'An analysis for a third area, Savannakhet Province, Lao PDR, was also completed utilising field data collected under the SUFORD project; these findings are not presented here.
} 
Figure 1. Workflow of the analysis.

Table 1. Pilot area biomass plot summaries.

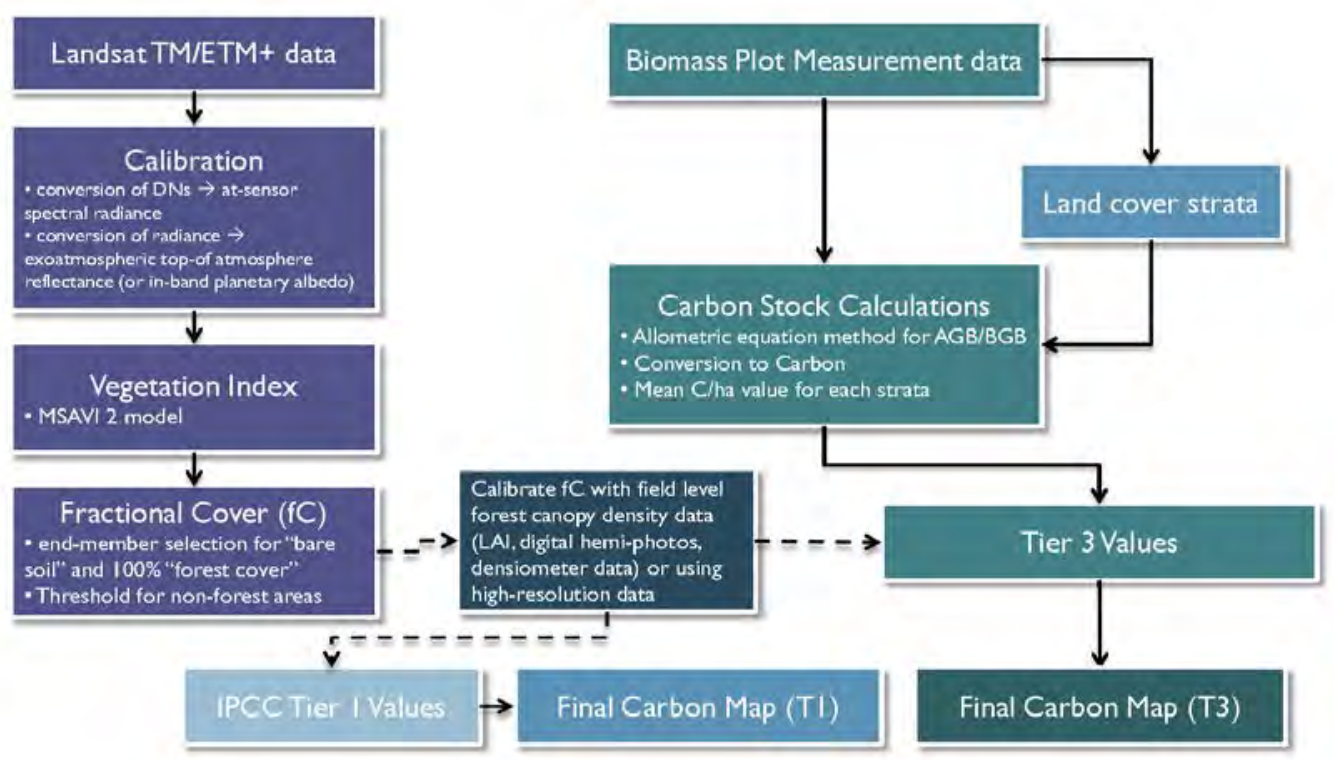

Vientiane Prefecture, Lao PDR and Bac Kan Province, Viet Nam. In Bac Kan Province, data was collected supporting the MRV system at two scales - province-wide and at two community forest areas belonging to $\mathrm{Na}$ Muc village, Van Minh Commune and Tu Dooc village Lang San Commune, both in $\mathrm{Na}$ Ri District. The area is located about 200 kilometres north of Hanoi. The community forest areas are tropical moist broadleaf evergreen forests.

In Sangthong District, data was collected by the Faculty of Forestry, National University of Laos in a tropical moist deciduous forest area. This area is located approximately 80 kilometres northeast of the capital city of Vientiane and is the district where the Faculty of Forestry maintains its Training Model Forest (TMF).

Table 1 shows the number, type and dimensions of biomass plots established at each study site and the number of trees inventorised.
The plot level tree inventory data were logged in an Excel file and uploaded to the online forest carbon MRV system, which estimates the carbon stock at the plot, parcel (or strata) and project levels.

\section{Remote Sensing Analysis}

Landsat data was first calibrated converting digital numbers (DNs) to at-sensor spectral radiance and then exoatmospheric top-of-atmosphere reflectance, also known as in-band planetary albedo (Chander et al., 2004). Data was then converted to a vegetation index using the Modified Soil Adjusted Vegetation Index 2 (MSAVI 2) model (Qi et al., 1994). A "vegetation continuous fields" (VCF) or "fractional cover" (FC) data set was then developed using a spectral unmixing algorithm (Matricardi et al., 2010) from two end-members (forest and bare soil). The FC data was then stratified using a land-cover

\begin{tabular}{cccc}
\hline Pilot Area & Number of Plots & Number of Trees & Plot Type \& Dimensions \\
\hline \multirow{2}{*}{ Sangthong Dist., Laos } & 13 & 711 & Circular Nested 25 and $10 \mathrm{~m}$ radius \\
& 16 & 721 & Circular Nested 50 and 20 and $10 \mathrm{~m}$ radius \\
\hline \multirow{2}{*}{ Bac Kan Prov., Viet } & 32 & 1486 & Rectangular Nested $50 \times 40 ; 5 \times 40 \mathrm{~m}$ \\
Nam & 22 & Var. land use systems ${ }^{2}$ & Rectangular Nested $10 \times 10 \mathrm{~m}$ \\
\hline
\end{tabular}

${ }^{2}$ Field data collected by ICRAF-Viet Nam for a study, Carbon stock evaluation in some types of land use in Bac

Kan by Đỗ Hoàng Chung. We used the data in forest carbon mapping with Landsat data. 


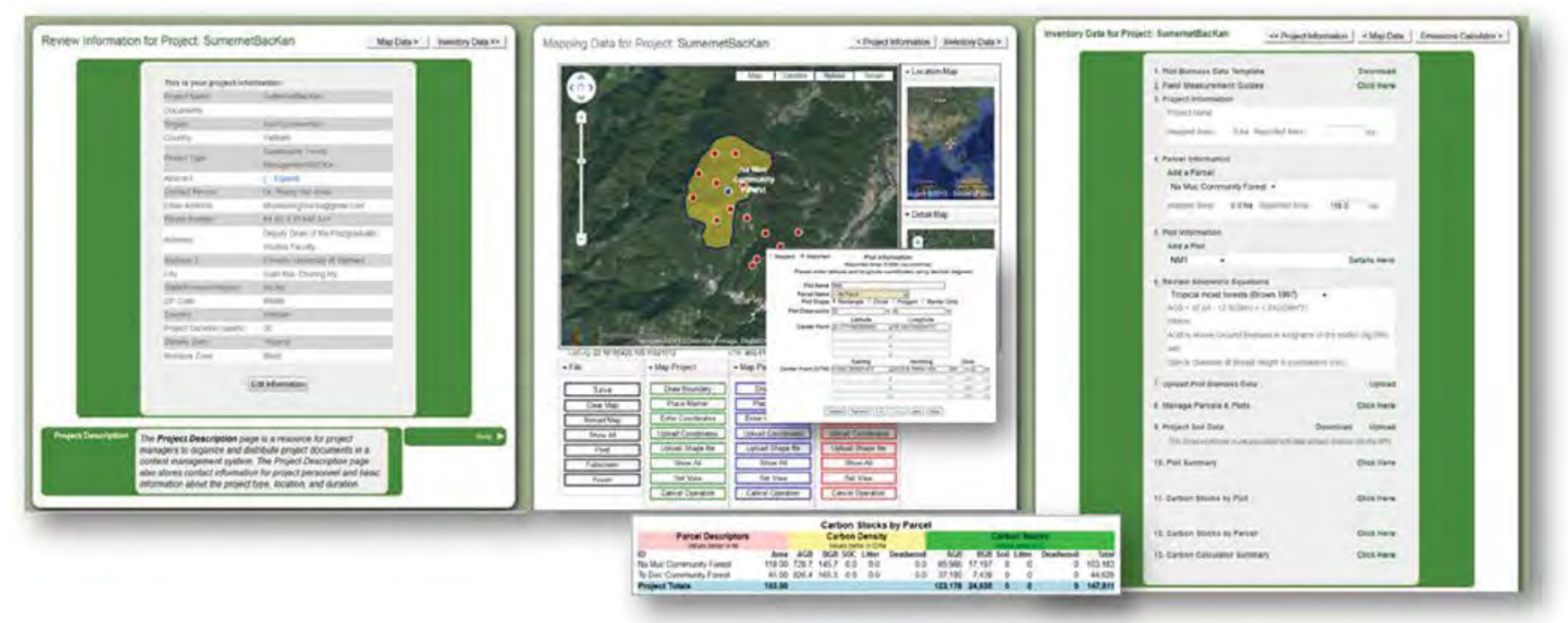

Figure 2. Three core components of the MRV system.

stratification map or through a forest/ non-forest level slice. For each stratum where we have the mean plot level carbon estimates, we then calibrated the FC data using a linear regression equation or downcalibrated the strata-specific biomass values using the FC pixel value. This produced a final forest carbon map. In the absence of plot level Tier 3 data, the FC data can be calibrated using field-collected canopy openness data again using regression equation coefficients. IPCC Tier 1 biomass estimates (IPCC, 2006) were then applied to the calibrated FC data product for the forest strata. The output was a Tier 1 downscaled forest carbon map and a more realistic estimate than simply a "paint-by-numbers" approach of assigning the IPCC default value to polygons of the same forest type. Figure 1 shows the workflow of the method.

\section{Internet-Based Forest Carbon MRV System}

The MRV system is designed as a project management system. It is Internetenabled, with a secure login. Data is stored in a relational database which has redundant backup with bi-monthly system snapshots for restore capabilities. The core functions of the system include (1) a content management system and project registry; (2) geographic tools to support project boundaries, parcel (or strata) boundaries, and plot locations; (3) plot inventory data with tools and information to support sample plot design and data collection as well as carbon stock reporting; and (4) an emissions calculator tool designed to use either the Tier 3 biomass estimates from the plot inventory data or Tier 1 IPCC default parameters to calculate emissions ex ante or ex post in a project parcel. Figure 2 shows screenshots of the MRV system's first three core components.

\section{MRV Carbon Stock Reports and Carbon Maps}

The results of the carbon stock are reported from the online MRV system for each project site. The calculations incorporate the Tropical Moist Forest allometric equation (Eq. 1) developed by Brown (1997) and a default root-to-shoot ratio of 20 for below-ground biomass.

Tropical Moist Forest Allometric Equation (Eq. 1) $\mathrm{AGB}=42.69-12.8(\mathrm{DBH})+1.242\left(\mathrm{DBH}^{2}\right)$

Where:

AGB $=$ Above Ground Biomass in kilograms of dry matter (kgDM), and DBH $=$ Diameter at Breast Height in centimetres $(\mathrm{cm})$

Above- and below-ground biomass is calculated at the tree level in each plot using the allometric equation and root-toshoot ratio. The above- and below-ground 
Figure 3. Carbon stock reports for both pilot project areas.
Figure 4. Forest carbon maps resulting from the carbon mapping analysis.

\begin{tabular}{|c|c|c|c|c|c|c|c|c|c|c|c|c|}
\hline \multicolumn{13}{|c|}{ Carbon Stocks by Parcel } \\
\hline \multicolumn{2}{|l|}{$\begin{array}{l}\text { Parcel Descriptors } \\
\text { Values below in ha }\end{array}$} & \multicolumn{5}{|c|}{$\begin{array}{l}\text { Carbon Density } \\
\text { Values below in tCha }\end{array}$} & \multicolumn{6}{|c|}{$\begin{array}{l}\text { Carbon Stocks } \\
\text { Vatues below in ic }\end{array}$} \\
\hline 然 & Area & AGB & BGB & SOC & Litter & Deadwood & AGB & BGB & Soil & Litter & Deadwood & Total \\
\hline Na Muc Community Forest & 118.00 & 728.7 & 145.7 & 0.0 & 0.0 & 0.0 & 85,986 & 17,197 & 0 & 0 & 0 & 103,183 \\
\hline To Doc Community Forest & 45.00 & 826.4 & 165.3 & 0.0 & 0.0 & 0.0 & 37,190 & 7,438 & 0 & 0 & 0 & 44,628 \\
\hline Project Totals & 163.00 & & & & & & 123,176 & 24,635 & 0 & 0 & 0 & 147,811 \\
\hline
\end{tabular}

\begin{tabular}{|c|c|c|c|c|c|c|c|c|c|c|c|c|}
\hline \multicolumn{13}{|c|}{ Carbon Stocks by Parcel } \\
\hline \multicolumn{2}{|c|}{$\begin{array}{l}\text { Parcel Descriptors } \\
\text { Values below in ha }\end{array}$} & \multicolumn{5}{|c|}{$\begin{array}{l}\text { Carbon Density } \\
\text { Values below in tC/hs }\end{array}$} & \multicolumn{6}{|c|}{$\begin{array}{l}\text { Carbon Stocks } \\
\text { Values below in kC }\end{array}$} \\
\hline ID & Area & AGB & BGB & SOC & Litter & Deadwood & AGB & BGB & Soil & Litter & Deadwood & Total \\
\hline Deciduous_Forest & $3,628.00$ & 93.3 & 18.7 & 0.0 & 0.0 & 0.0 & 338,574 & 67,715 & 0 & 0 & 0 & 406,288 \\
\hline Project Totals & $3,628.00$ & & & & & & 338,574 & 67,715 & 0 & 0 & 0 & 406,288 \\
\hline
\end{tabular}

biomass density, reported in tons of carbon per hectare, is then computed for each plot. For all plots associated with a specific parcel, the mean above- and below-ground biomass is calculated. Total carbon stock is computed using the area of the parcel and the mean above- and below-ground biomass density derived from all plots associated with the parcel. Figure 3 shows the carbon stock reports for both pilot project areas indicating the project and parcel areas, the above- and below-ground carbon density values, and above- and below-ground carbon stocks.

The carbon mapping analysis of Bac Kan Province used subsets of two adjacent Landsat images for complete coverage of the provincial area. Data was processed to FC as per the method describe. A threshold value of $\mathrm{FC}=30$ was used to determine forest and non-forest. A Tier 1 forest carbon map was then developed by multiplying the FC value of all forest class pixels with the IPCC Tier 1 default biomass value of $130 \mathrm{tDM}$ per ha of above-ground biomass from table 4.7 of IPCC (2006). The result is a carbon stock estimate for the province of 44,901,883 tC or an average of $92 \mathrm{tC}$ per ha. A Tier 3 forest

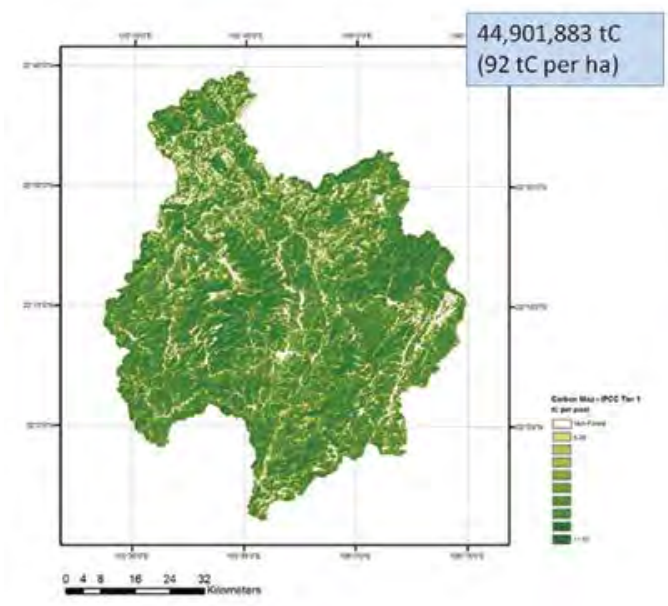

carbon map was developed integrating a land-use and land-cover data set and biomass data from field plots with the FC data product. The output map estimates carbon stock in Bac Kan at 28,928,355 tC or an average of $60 \mathrm{tC}$ per ha (see Figure 4).

\section{Conclusion}

A fully deployed, Internet-based forest carbon system that supports project geographic strata and plot data as well as tree inventory data from field-level biomass plots can serve as a major linchpin for a REDD+ MRV scheme. Tier 3 reporting from this online tool integrated with robust methods for mapping forest carbon using satellite remote sensing data can help scale up this REDD+ MRV system, lowering MRV costs associated with a field-level-only approach. We successfully demonstrated the Internetbased forest carbon MRV system and the remote sensing forest carbon mapping method at two project sites in Lao PDR and Viet Nam. The system is currently online as a version 1.4.1 deployment at http://mrv. carbon2markets.org.

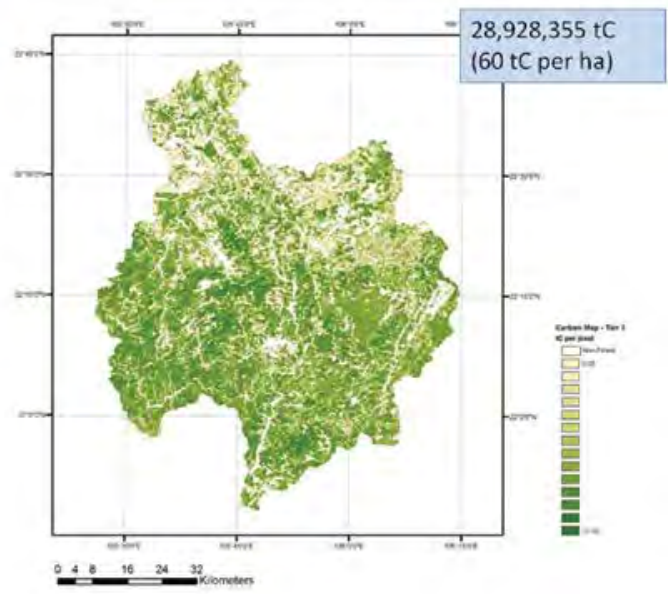




\section{References}

Agrawala, S., Ballard, T., Bresch, D., Herweijer, C., Nelson, J., Rambharos, M., \& Simon Zadek. (2009). Taskforce on Low-Carbon Prosperity: Recommendations (No. 121009) (p. 125). Geneva: World Economic Forum. Retrieved from http://www.weforum. org/reports/taskforce-low-carbonprosperity-recommendations

Brown, S. (1997). Estimating biomass and biomass change of tropical forests: A primer (No. FAO Forestry Paper - 134)). Rome: FAO. Retrieved from http://www.fao.org/docrep/w4095e/ w4095e00.htm

Chander, G., Meyer, D. J., \& Helder, D. L. (2004). Cross calibration of the Landsat-7 ETM+ and EO-1 ALI sensor. IEEE Transactions on Geoscience and Remote Sensing, 42(12), 2821-2831. doi:10.1109/TGRS.2004.836387

Harris, N. L., Brown, S., Hagen, S. C., Saatchi, S. S., Petrova, S., Salas, W., ... Lotsch, A. (2012). Baseline map of carbon emissions from deforestation in tropical regions. Science, 336(6088), 1573-1576. doi:10.1126/science.1217962
IPCC. (2006). 2006 IPCC guidelines for national greenhouse gas inventories. (S. Eggleston, L. Buendia, K. Miwa, T. Ngara, \& K. Tanabe, Eds.). Hayama: IGES. Retrieved from http://www. ipcc-nggip.iges.or.jp/public/2006gl/

IPCC. (2007). Climate change 2007: The physical science basis. (S. Solomon, D. Qin, M. Manning, M. Marquis, K. Averyt, M. M. B. Tignor, ... Z. Chen, Eds.). Cambridge: Cambridge University Press. Retrieved from http://www.cambridge.org/features/ earth_environmental/climatechange/ wg1.htm

Matricardi, E. A. T., Skole, D. L., Pedlowski, M. A., Chomentowski, W., \& Fernandes, L. C. (2010). Assessment of tropical forest degradation by selective logging and fire using Landsat imagery. Remote Sensing of Environment, 114(5), 1117-1129. doi:10.1016/j.rse.2010.01.001

Qi, J., Chehbouni, A., Huete, A. R., Kerr, Y. H., \& Sorooshian, S. (1994). A modified soil adjusted vegetation index. Remote Sensing of Environment, 48(2), 119-126. doi:10.1016/0034-4257(94)90134-1

\section{EBLU2011-02CMY(C)-SKOLE}

\section{PROJECT TITLE}

Developing an MRV System for REDD+: Scaling Up from Project Level to a National Level REDD+ MRV Systems for Laos and Viet Nam

\section{COUNTRIES INVOLVED}

Lao PDR, USA, Viet Nam

\section{PROJECT DURATION}

2 years

\section{APN FUNDING}

US\$ 65,000

\section{PROJECT LEADER}

Dr. David L. SKOLE

Global Observatory for Ecosystem Services

Department of Forestry

Michigan State University

1405 S Harrison Rd., Suite 101

East Lansing, MI 48812 USA

Tel.: +1 5173550181

Email: skole@msu.edu

Website: www.goes.msu.edu

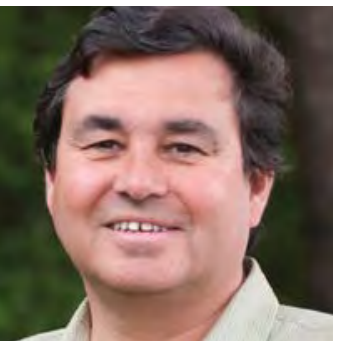

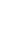

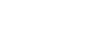




\title{
Assessing Potential Co-Benefits of REDD+ in Shifting Cultivation Landscape
}

\author{
Kazuhiko Takeuchi, Luohui Liang', Narit Yimyam, Oloth Sentaheuanghong, Krishna Gopal Saxena, Jintana Kawasaki \\ 'Corresponding Author \\ United Nations University Institute for Sustainability and Peace (UNU-ISP), Tokyo \\ Email: liang@unu.edu
}

\begin{abstract}
This study aimed to assess the potential and options to achieve co-benefits of REDD+for carbon sequestration, biodiversity conservation and livelihood improvement in shifting cultivation landscape. Carbon stocks and biodiversity in different land-use/ land-cover types were inventorised from selected cultural landscapes. A socioeconomic survey was employed to assess the economic benefits of different land uses and the opportunity costs for alternative land uses. The integration of biophysical and socioeconomic data led to the identification of potential land-use practices to enhance carbon stocks and economic benefits, as well as biodiversity. Good land-use practices were demonstrated to local farmers and officials. The results of this assessment were used to train local stakeholders to manage, measure and monitor forest carbon pools.
\end{abstract}

KEYWORDS: REDD+, co-benefits, shifting cultivation, landscape, Laos, Thailand

\section{Project Objective and Relevance to the APN's Science and Policy Agendas}

Traditional shifting cultivation, widely practiced in the tropical forests, integrates a short cropping phase and a long forest fallow phase in rotation. In the cropping phase, many cereals, root crops and vegetables are cultivated to ensure a balanced diet for shifting cultivators; soil seed bank and tree stumps conserved through zero tillage to facilitate subsequent forest regeneration. In the fallow phase, forests not only provide a range of products but also contribute nutrient inputs to surface soil through uptake from deep soil horizons and nitrogen fixation, but also sequester carbon, control weeds, and check soil erosion for the succeeding cropping phase. Apart from forest fallows, natural forests are maintained by shifting cultivators to timber production, recharging water sources and spiritual values. Nevertheless, shifting cultivation is under increasing pressure to shorten its forest fallow phase and change to other land uses with implication on local livelihoods, carbon sequestration and biodiversity.

With the support of the Asia-Pacific Network for Global Change Research (APN) and the United Nations University (UNU), in partnership with National Agriculture and Forest Research Institute (NAFRI) in Laos and Chiang Mai University (CMU) in Thailand, we are undertaking a three-year project to assess the potential and options for shifting cultivators to build on traditional knowledge and achieve co-benefits of carbon 
sequestration, biodiversity conservation and livelihood improvement through the new global initiative for reducing deforestation and forest degradation, including the role of conservation, sustainable management of forests and enhancement of forest carbon stocks (REDD+). The project promotes regional cooperation on sustainable land management between Laos, Thailand, India, China and Japan, and is improving the scientific and technical capabilities of participating countries through research collaboration and exchange. The project is also providing scientific input to policy-making in REDD+ implementation, especially at national and local levels; contributing to relevant policy debates; and assisting in developing policy guidelines at national and international levels through the Asia-Pacific Forest Partnership and the Mountain Partnership, where UNU is formally represented, and other platforms as opportunities arise.

\section{Progress to Date}

The project selected two study villages, one each in Northern Thailand (Tee Cha, a Pwo Karen village in Mae Hong Son Province) and Northern Laos (Laksip, a Khmu village in Luang Prabang Province). Rotational shifting cultivation remains the major livelihood in the study village in Northern Thailand, while in Northern Laos, this land use is being replaced with timber plantations. The two villages offer a good comparison of traditional land-use systems in transition, with consequences on carbon stock, biodiversity and livelihoods. Significant progress has been made since project inception in 2011. Land-use survey

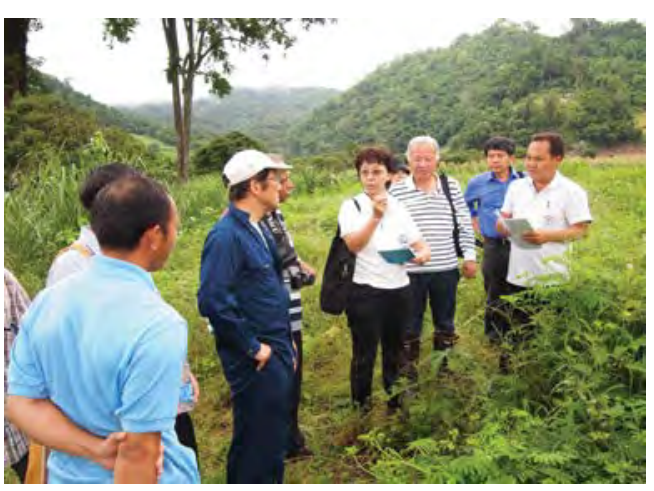

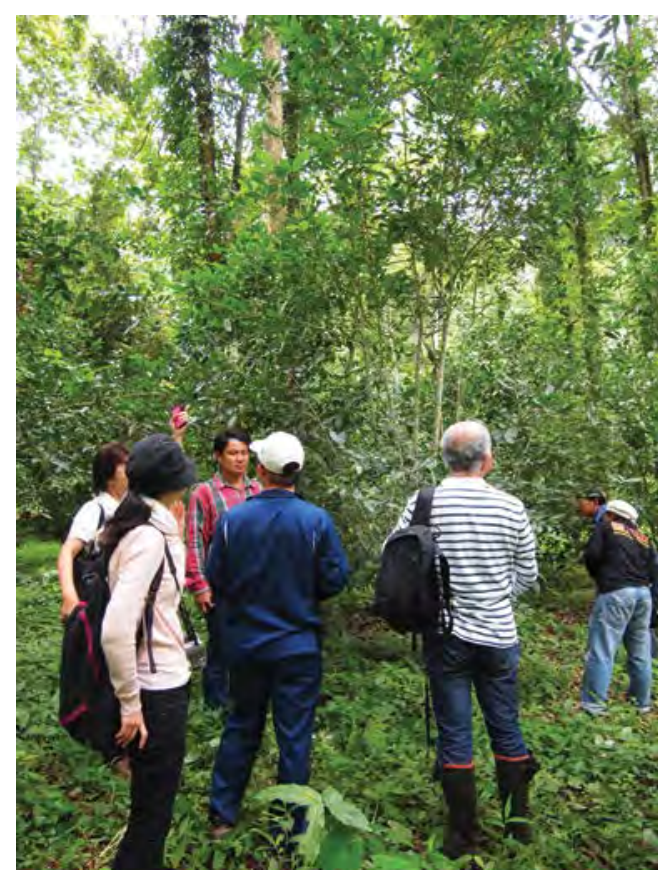

and mapping has provided a basis for stratification of the village landscape into relatively homogenous land-cover/land-use units for assessment of carbon storage, biodiversity and identification of land-use practices rich in these resources. The inventory brought out the spatial distribution of carbon stocks on the village landscape, with the highest carbon intensity in the natural forests, followed by forest fallows and permanent crop fields. The carbon stock increased with the age of fallows. Fallows held carbon stocks comparable to teak plantations but larger than the permanent fields. The opportunity cost of forest conservation to a coffee plantation at the project site in Thailand was US\$0.47/ton $\mathrm{CO}_{2}$ and to teak plantations at the project site in Laos was US\$0.952/ton $\mathrm{CO}_{2}$. The research also analysed historical land-use and carbon stock changes and projected future land-use scenarios including possible baseline/reference levels. The knowledge on carbon stocks, biodiversity and economic benefits of different land use practices obtained through field surveys and laboratory analyses, was shared with local communities and governments for community-based management of terrestrial carbon pools and appreciation of the potentials for co-benefits of carbon, biodiversity and local livelihoods. Good 
land management practices were identified and demonstrated. One example to establish good practices to enhance soil carbon stock and plant diversity in teak plantation, such as the abandonment of farmers' practice to ground fire every year, was demonstrated by making a comparison of two demonstration plots in Laksip village, Laos.

A training course was organised to train farmers and local forest officers at Tee Cha village, Thailand for building local capacity for meeting the monitoring, reporting and valuation requirements of the REDD+ programme. Organisation of several project workshops has facilitated the exchange of knowledge and experiences among project team members and development of working guidelines on carbon stock measurement as well as community-based monitoring, reporting and verification (MRV). The results and findings will be synthesised and disseminated at national and international levels in the final year of the project.

\section{Project Publications}

Takeuchi, K. (2012). Forest carbon stocks in shifting cultivation of Thailand and Laos. APN Science Bulletin, (2), 142-144.

Takeuchi, K., Takahashi, S., Lim, A., Kawasaki, J., \& Liang, L. (2011, September). REDD+ for forest communities based on lessons learnt from forest conservation efforts in Laos and Thailand. APN Newsletter, 17(3), 3-4.

\section{Acknowledgments}

We would like to appreciate financial support of APN and UNU as well as collaboration of local communities and governments at project sites.

\section{EBLU2011-01CMY(R)-TAKEUCHI}

\section{PROJECT TITLE}

Critical Analysis of Effectiveness of
REDD+ for Forest Communities and
Shifting Cultivation, Based on Lessons
Learnt from Conservation Efforts in Laos
and Thailand

\section{COUNTRIES INVOLVED}

Japan, Lao PDR, Thailand

\section{PROJECT DURATION}

2 years

\section{APN FUNDING}

US\$ 120,000

PROJECT LEADER

Prof. Kazuhiko TAKEUCHI

United Nations University Institute for

Sustainability and Peace

53-70, Jingumae 5-chome, Shibuya-ku, Tokyo 1508925, Japan

Tel: +8135467 1237

Email:Takeuchi@unu.edu

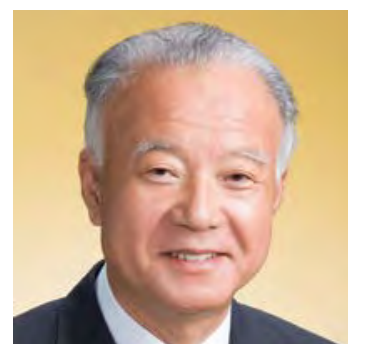




\title{
Capacity Building of ALOS Satellite Data to Support Mapping and Monitoring Deforestation and Degradation in Indonesia
}

\author{
Tomotaka Sekiya' \\ 'Remote Sensing Technology Center (RESTEC) of Japan, Japan \\ Email: sekiya@restec.or.jp
}

\begin{abstract}
RESTEC and partners designed a workshop in Indonesia and a training course in Japan with the aim to improve Indonesia's capability of forest monitoring, transferring Japanese technologies and knowledge of analysing satellite data, particularly ALOS/PALSAR, and contribute to decision-making in forestry and carbon emissions in Indonesia. A one-day workshop and two-week training course were completed where participants shared very useful information. Eight Indonesian GIS/RS experts learned the basic theory of Radar sensor, in particular ALOS/ PALSAR, geometric and radiometric features of SAR and other basic knowledge. They also practised techniques and procedures using PALSAR observation data for forest monitoring and forest biomass estimation. With these techniques and knowledge, they can advance their research and operational forest-monitoring work more efficiently. Collaborators agreed that the training was useful and that these kinds of activities to improve Indonesian capacity should be continued.
\end{abstract}

KEYWORDS: satellite, ALOS, PALSAR, forest, REDD+, Indonesia 


\section{Introduction}

Since the 1990's, forest monitoring using remote sensing in Indonesia has been carried out using Landsat images (optical images). Cloud cover is considered to be the main obstacle in obtaining consistent images that cover the whole area of the country and $10 \%$ of images are generally always cloud covered. This situation contrasts with the increasing need to obtain more rapid, reliable, and consistent information of the current status of land use and land cover as well as their dynamic changes over time.

Radar data has the capacity to penetrate cloud and is essential to overcome the cloud cover problem. Integrating data from the Phased Array type L-band Synthetic Aperture Radar (PALSAR) on the Advanced Land Observing Satellite (ALOS) into current forest monitoring systems will provide cloud free results. In addition to the capability of providing cloud cover-free information, ALOS/PALSAR data, specifically dual polarimetric data, also has the potential to discriminate between forest cover types and other major types of land cover. This implies that in the establishment of improved (new) reliable methods, solely for forest cover monitoring systems, detecting change and monitoring deforestation and degradation using ALOS/PALSAR data is promising.

\section{Preparatory Phase}

A workshop was held on 19 July 2011 in Bogor, Indonesia, and participated by Indonesian experts from ministries, agencies and universities. The participants shared information on research and capacity building activities related to

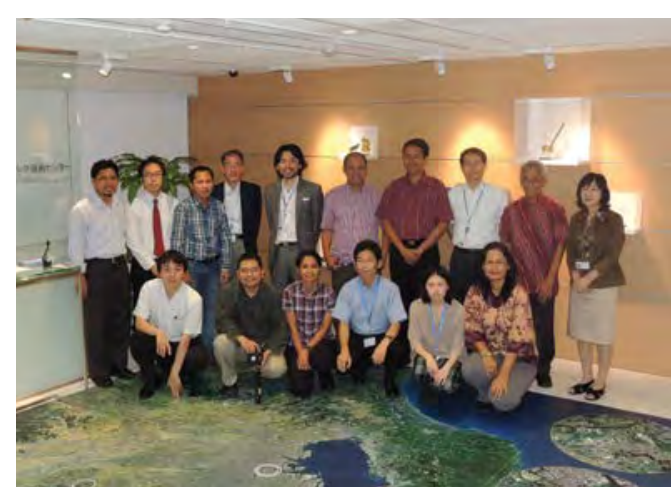

Figure 1. Participants of the workshop.

forest monitoring by remote sensing in Indonesia, as well as needs of the Indonesian government. Based on the information shared, a training course was developed.

Before the training course, RESTEC developed a basic method of forest monitoring with PALSAR data, customising RESTEC's existing techniques, experiences and algorithms, which mainly focused on domestic forest areas in Japan. The existing techniques needed to be customised and adjusted to Indonesian forests because of the very different forest types between the two countries.

Figure 2 is a colour composite image analysed from PALSAR FBD data observing a forest area in Indonesia on 4 October 2008. FBD contains $\mathrm{HH}$ and HV polarisations. RESTEC generated the forest/non-forest map from PALSAR data observed on 25 February 2011. Figure 3 is the forest/non-forest map derived from Figure 1. RESTEC calculated the intensity of backscatter pixel by pixel, and settled the threshold at $-13 \mathrm{db}$ in order to classify forest and non-forest. In the existing methodology, which we used to analyse forest areas in Japan, we set the threshold at $-11.5 \mathrm{db}$.

\section{HIGHLIGHTS}

»A workshop was held in Bogor, Indonesia, where participants shared useful information for satellite monitoring of forests.

» A two-week training course was conducted in Tokyo, Japan. Participants learned various techniques and procedures in using PALSAR observation data for forest monitoring and forest biomass estimation. 


\section{Training Implementation}

Eight Indonesian GIS/RS experts who have basic knowledge and experience of GIS/RS were selected as trainees. They were from the Ministry of Forestry, Republic of Indonesia (MoF); the Agency for the Assessment and Application of Technology (BPPT) and the local government of Landak Regency (West Kalimantan Province).

\section{Interferometry}

Through the training course, the participants learned Interferometric SAR (InSAR) and Differential InSAR (DInSAR) techniques. Interferometry is used to analyse interference of phase information of two or more pairs of SAR data. In this technique, changes in surface condition can be detected, including areas of deforestation and degradation.

\section{Polarimetery}

Trainees learned about SAR Polarimetry, which is very important to classify forest and non-forest areas. ALOS/ PALSAR full polarisation observation (PLR) mode can detect 4 pairs of polarisations $(\mathrm{HH}, \mathrm{HV}, \mathrm{VV}$ and $\mathrm{VH})$. Trainees understood the features of polarisations and generated a colour composite image from different polarisation images. All participants obtained a series of techniques to generate colour composite images and forest/non-forest maps from PLR data.

\section{Change Detection}

Trainees learned the technique to detect deforestation and degradation using multi temporal sets of SAR data. Satellites can observe a certain area over and over again, particularly since radar sensors are not affected by weather. This is one of the advantages of satellite remote sensing and periodical observation and is very important in MRV for REDD+.

\section{Above-Ground Biomass}

Trainees learned to estimate Above-Ground Biomass (AGB) directly from Radar backscattering or Sigma0. After applying radiometric terrain correction, they calculated the relationship between Sigma0 and AGB. Some research studies note that Radar backscattering is saturated around 100t/ha of AGB. Therefore, trainees understood that this technique should only be applied in low biomass areas in Indonesia, such as plantations with young trees.

\section{Conclusions}

The two-week training course was successfully completed and eight Indonesian GIS/RS experts learned the basic theory of Radar sensor, in particular ALOS/PALSAR, geometric and radiometric features of SAR and some other basic knowledge. They also practised the procedures of PALSAR Level 1.0 and 1.5 data analysis, InSAR and
Figure 2 (left). PALSAR FBD color composite image on 4 Oct 2008. Red color on $\mathrm{HH}$, green on HV and blue on VV. Forest areas are shown as light green.

Figure 3 (right). Forest/non-foresty map derived from FBD data in Oct 2008. The forest area is shown in green, and non-forest area in yellow.
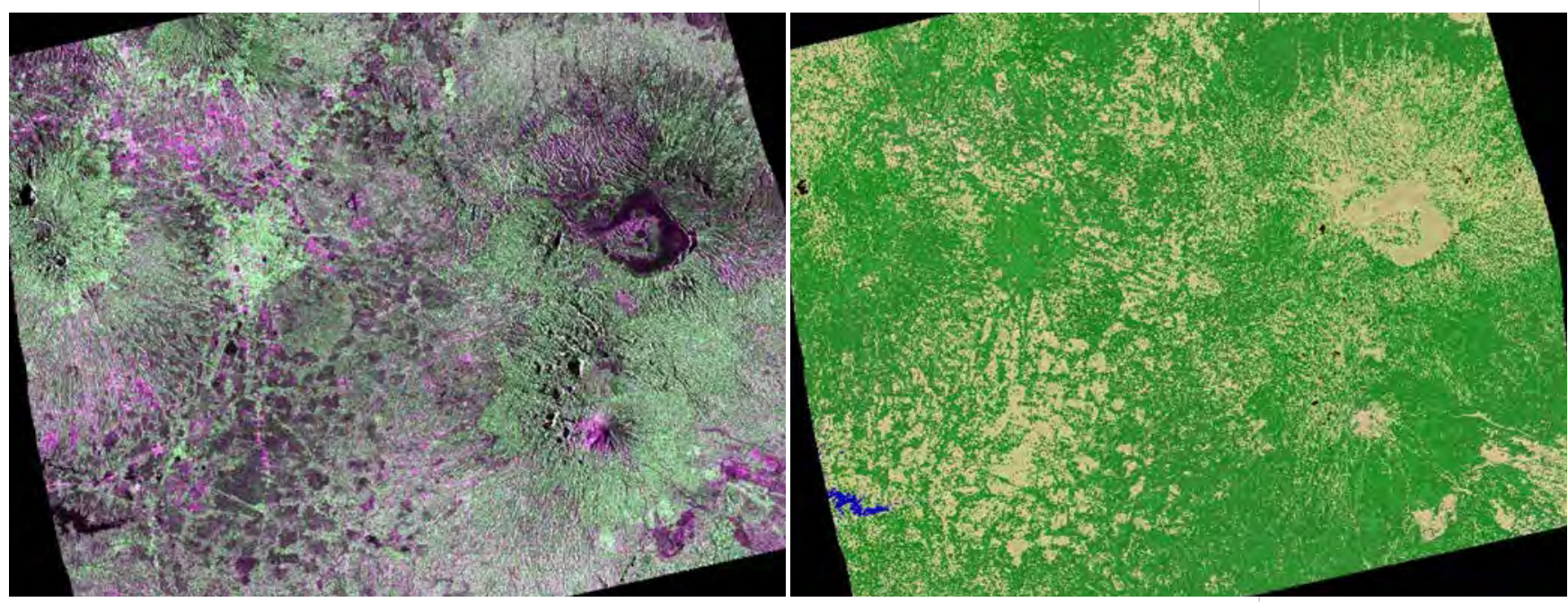
DInSAR analysis, forest area detection by dual polarisation, PALSAR Polarimetry analysis, and forest biomass estimation. The knowledge and techniques learned are essential in order to utilise radar satellite data for forest monitoring. With these techniques and knowledge, participants can advance their research and operational forest monitoring more efficiently than before.

All participants agreed that the training course was useful and these kinds of activities should continue in order to improve Indonesian capacity. As human resources in Indonesia are very limited and satellite data access - including financial aspects - is also an issue, we agreed that current and future forest and remote sensing-related projects should collaborate.

\section{Future Directions}

As ALOS completed its operation at the beginning of this project, we focused on the new satellite ALOS-2, which is to be launched in 2013, and prepared with ALOS archive data. ALOS- 2 is expected to have greater capability and its observation data will provide more information to monitor forests. However, there is still a large gap between the requirements from the forest side and the capability of the satellite, in particular radar data. For example, the Ministry of Forestry has periodically generated their land classification map with 23 categories while PALSAR has provided the land classification map with only 10 categories so far.

The participants of this project agreed that we should continue capacity building activities to provide human resources, equipment, and the other environments to use ALOS-2 data. The project provided Indonesian GIS/RS experts with basic knowledge and techniques for ALOS-2 data. They are expected to assimilate, improve and expand their experience to other scientists in Indonesia and develop teams to use ALOS-2 data.

\section{Acknowledgments}

We would like to thank the APN for its strong financial support and Dr. Shimada of Japan Aerospace Exploration Agency (JAXA) who presented JAXA's forest monitoring activities and its state-of-the-art technologies. We would also like to thank all the workshop participants for sharing important information.

\section{EBLU2011-03CMY(C)-SEKIYA}

\section{PROJECT TITLE}

Capacity Building of ALOS Satellite Data to Support Mapping and Monitoring of Deforestation and Degradation in Indonesia

\section{COUNTRIES INVOLVED}

Indonesia, Japan

\section{PROJECT DURATION}

2 years

\section{APN FUNDING}

US\$ 58,000

\section{PROJECT LEADER}

Tomotaka SEKIYA

TOKYU REIT Toranomon Bldg. 3F

3-17-1, Toranomon, Minato-ku, Tokyo 105-0001, Japan

Tel: +81364356733

Email: sekiya@restec.or.jp

Website: http://www.restec.or.jp/

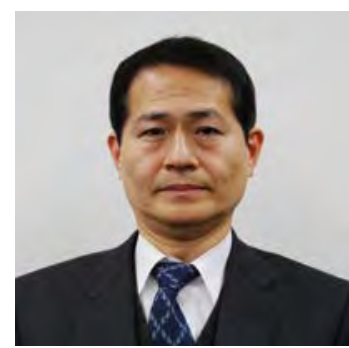
. 


\title{
Participatory Approaches to Forest Carbon Accounting to Mitigate Climate Change, Conserve Biodiversity and Promote Sustainable Development
}

\author{
Henry Scheyvens', Makino Yamanoshita, Agus Setyarso, Saykham Boutthavong, Enrique Ibarra Gene and Kimihiko \\ Hyakumura \\ 'Corresponding Author \\ Institute for Global Environmental Strategies, Japan \\ Email:scheyvens@iges.or.jp
}

ABSTRACT: This action research project aims to develop, test and implement approaches to engage local communities in forest biomass monitoring. It is expected that the information generated will provide further forest management options to communities and can be integrated into national REDD+ MRV systems. The action research is being conducted at sites in Indonesia, Viet Nam and Laos, and follows a step-by-step process involving the establishment of facilitation teams; consultations; training of trainers; mapping of forest boundaries and strata; training of communities and community institution building; establishment and measurement of permanent sample plots; analysis of the data; outreach, and next steps. The research has found that effective training is critical to the success of community-based forest biomass monitoring. The trainers must possess expert knowledge on forest monitoring principles and methods, and they must also be experts in community facilitation. To establish self-reliant community-based forest biomass monitoring teams, monitoring systems have to be simplified, without sacrificing their credibility, and the training of communities has to be tailored to reflect local needs, institutions and knowledge systems. A manual as a resource for the training of trainers, drawing on the action research experience, is planned to be drafted by project partners.

KEYWORDS: participation, community, forest, REDD+, measurement, biomass 
Figure 1. Action research process.

\section{Project Background}

The project is aimed at achieving the following objectives:

- develop, testandimplement approaches to engage local communities in monitoring forest biomass; and

- use the information generated to assess the feasibility of alternative forest management options, including REDD+.

In addition, the project is considering how communities could be involved in national REDD+ monitoring, reporting and verification (MRV) systems.

\section{Relevance to the APN's Science and Policy Agendas}

The project is generating new knowledge on how the capacity and institutions of local communities can be built for them to participate in forest monitoring, and on how the information generated can contribute to forest management and national MRV. The action research methods and results are being shared with policy makers involved in REDD+ readiness processes, and presented at side events of the international climate change negotiations.

\section{Work Undertaken and Results to Date}

The action research process is illustrated in Figure 1. The action research is being undertaken at project sites in Indonesia, Viet Nam and Laos. In addition to the sitespecific action research, project partners are now developing a training of trainers manual on community-based forest biomass monitoring.

\section{Regional Collaboration}

\section{Indonesia}

The main action research partners in Indonesia are the National Forestry Council of Indonesia (DKN), ARuPA, IGES and the participating communities. The project also enjoys the support of the district governments. Feasibility studies resulted in the selection of Semoyo, Burat and Terong villages in Java for the research.

The activities conducted have included consultations with local authorities and communities; meetings to design the research; awareness on climate change and REDD+; training of trainers; training of the communities; forest measurement; data

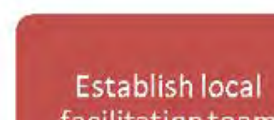

facilitation team
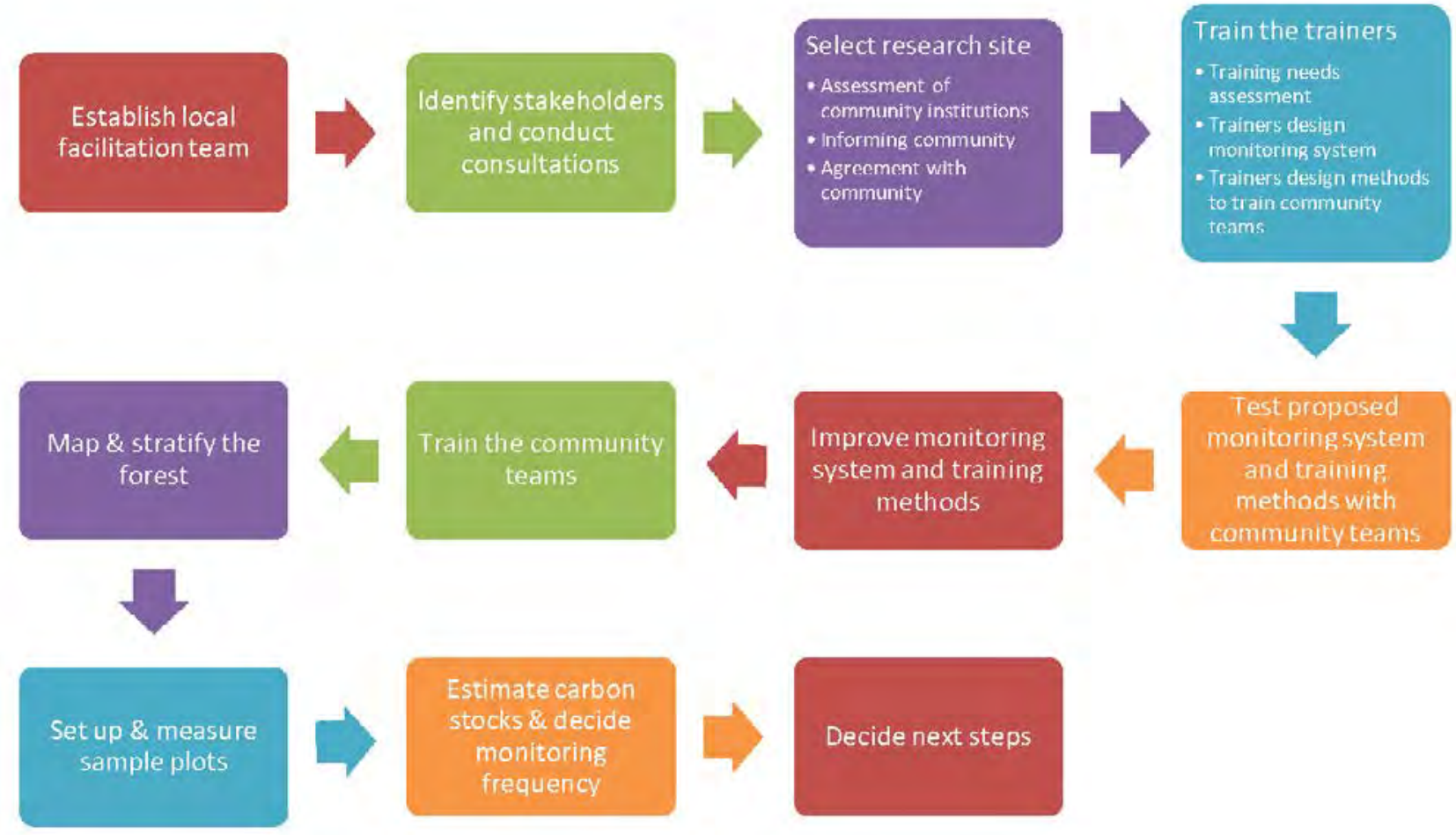
entry and processing; outreach; and training on project design documents.

Outreach has been an important aspect of the project. Semoyo leaders prepared an extra curriculum class on environment and climate change, and they are using radio to disseminate and share lessons from their forest monitoring. A participatory carbon assessment workshop was held in Gunung Kidul District and was attended by the leaders of each village and the district government heads of forestry and environment.

Re-measurement of plots has shown carbon stocks have increased by more than $4 \mathrm{tC} / \mathrm{ha}$, in spite of timber harvesting that took place between the first and second measurement (a period of one year), but this is without payments for REDD+, so these stock increases would not pass additionality tests. For them to implement REDD+, communities would have to postpone their timber harvesting to increase carbon stocks further. When present income is destined to cover basic needs, this is a choice that communities may be reluctant to make. A household survey was conducted in the participating communities and found that they operate under financial stress.

Training of the communities on preparing project design documents (PDDs) for forestry projects has also been conducted. PDDs based on the Climate, Community, and Biodiversity Alliance Standards are now being drafted by the communities.

\section{Viet Nam}

In Viet Nam, the project partners are Vietnam Forestry University (VFU), IGES and selected communities involved in the Cao Phong reforestation project, which is a small scale $\mathrm{A} / \mathrm{R}$ CDM project that was registered with the UNFCCC in 2009. The project is located in Xuan Phong and Bac Phong communes, Cao Phong district, Hoa Binh province.

In 2012, two training workshops were held at VFU for the project facilitators: a 5-day training workshop on the concept of participation; and a 4-day training workshop on community-based forest monitoring. $\mathrm{Ru} 3$ Village, one of the 11 reforestation project villages, was selected for testing some of the proposed elements of the forest monitoring system. The area reforested by the village was mapped using GPS and GIS, and a social survey was conducted. The test training of the community on forest monitoring generated important lessons on the need for good training preparation, effective teaching methods, simple yet credible measurement methods, and flexibility to test alternative measurement options.

\section{Lao PDR}

In Laos, the project is being led by the National University of Laos (NUoL), with support from IGES. The project is being implemented with 4 villages in Sangthong District, Vientiane, that have a total community forest area of 1,887 ha.

The project initially focused on building the capacities of the facilitation team, the local authorities and the participating communities. A training workshop on forest carbon accounting was conducted for the research facilitators, and workshops on climate change, forest management and REDD+ were conducted with the local authorities and communities. More recently, the project

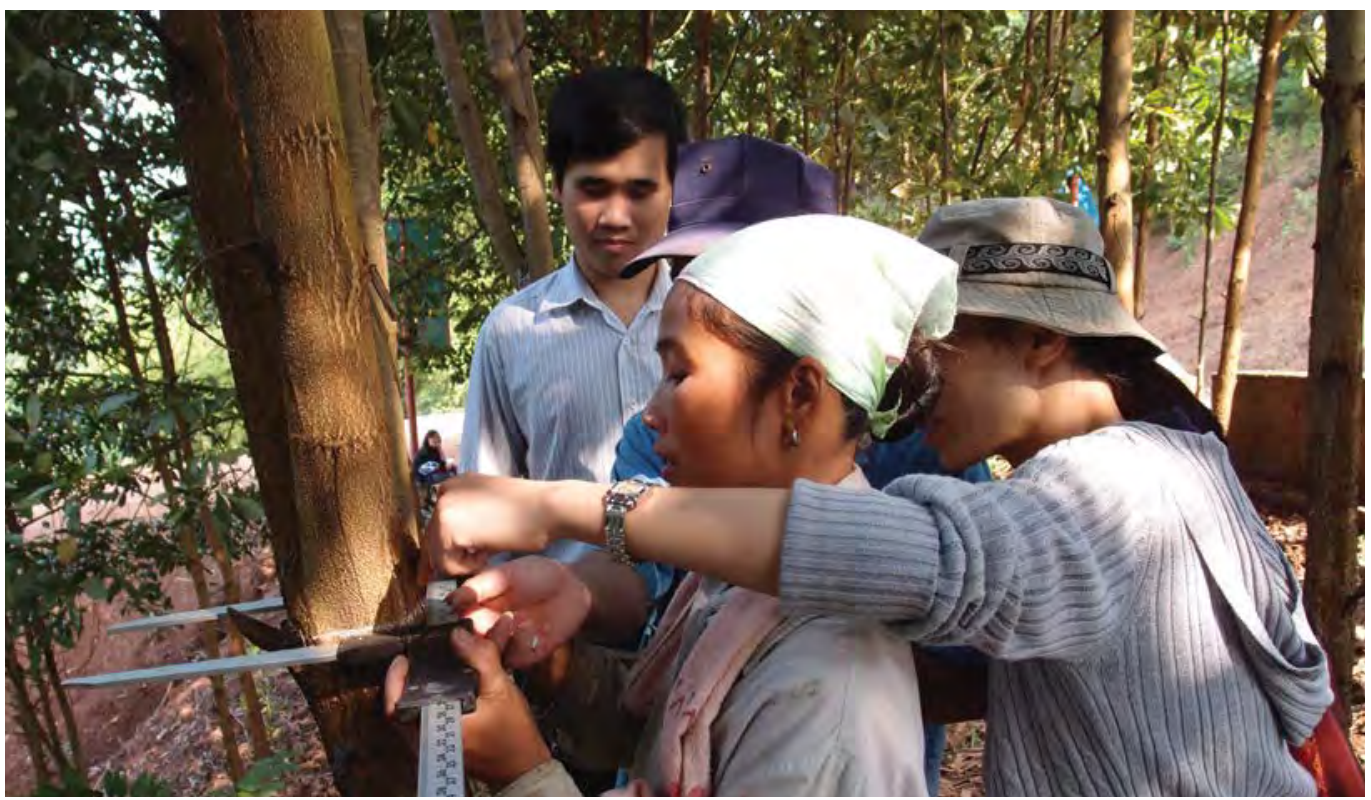

Figure 2. Test training on community-based forest biomass monitoring with Ru 3 Village. 
activities have included finalising the socioeconomic baseline dataset of the participating communities; developing training materials and a field guide; conducting community awareness and training; establishing the forest biomass inventory teams and guiding them in the establishment and measurement of sample plots; and preliminary field survey data management and analysis. Linking the monitoring to community livelihoods has been found to be a significant challenge for the action research.

\section{Conclusion}

The research shows that effective training is critical to the success of community-based forest biomass monitoring approaches. The trainers must possess expert knowledge on forest monitoring principles and methods, and they must also be experts in community facilitation. Project partners are now drafting a manual as a resource for the training of trainers, drawing on the action research experience.

The preliminary results of the action research are encouraging in the sense that the communities have generally participated enthusiastically in the monitoring, and developed the competence to take accurate forest measurements through the training. A challenge the research is now addressing is how to maximise the use of the information generated, both for climate change mitigation and community livelihoods.

\section{Project Publications}

Rabhi, A., Bhattacharya, A., Fujisaki, T., Fukuda, K., Fukui, A., Huang, J., ... Muchtar, M. (2012). Measurement, Reporting, and Verification (MRV) for low carbon development: Learning from Experience in Asia. (K. Usui \& Y. Takagi, Eds.). Retrieved from http:// pub.iges.or.jp/modules/envirolib/view. php\%3Fdocid $=4280$

Scheyvens, H. (2012). Community-based forest monitoring for REDD+: Lessons and reflections from the field (p. 10). Hayama: IGES. Retrieved from http:// pub.iges.or.jp/modules/envirolib/view. php? docid $=4124$

Scheyvens, H., Ibarra-Gene, E., Yamanoshita, M., \& Hyakumura, K.(2012). Participatory approaches to forest carbon accounting to mitigate climate change, conserve biodiversity and promote sustainable development. APN Science Bulletin, (2), 145-146.

\section{Acknowledgments}

The principal project researcher is grateful to the Ministry of the Environment of Japan for funding IGES research on REDD+. These funds have been used in a complimentary manner with the APN funding to undertake the research on community-based forest biomass monitoring.

EBLU2011-04CMY-SCHEYVENS

\section{PROJECT TITLE}

Participatory Approaches to Forest
Carbon Accounting to Mitigate Climate
Change, Conserve Biodiversity and
Promote Sustainable Development

\section{COUNTRIES INVOLVED}

Cambodia, Indonesia, Japan, Lao PDR

\section{PROJECT DURATION}

3 years

\section{APN FUNDING}

US\$ 120,000

\section{PROJECT LEADER}

\section{Henry SCHEYVENS}

Natural Resources and Ecosystems Area, Institute for Global Environmental Strategies, 2108-11

Kamiyamaguchi, Hayama, Kanagawa,240-0115 Japan

Tel: +81468553878

Email: scheyvens@iges.or.jp

Website: www.iges.or.jp/en/fc/activity_cca.html

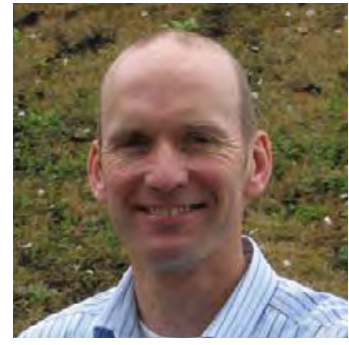




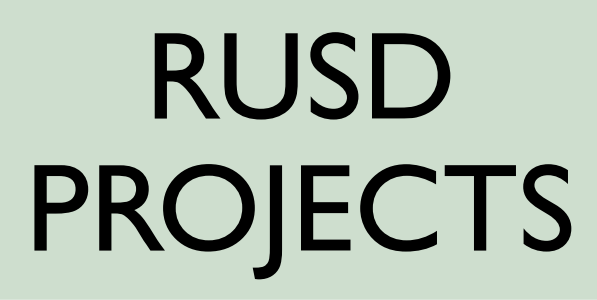

Focused Activities:

Resources Utilisation and Pathways for Sustainable Development 


\title{
Assessment and Promotion of Strategies and Techniques for the Reuse of Agricultural Straw Residues in China
}

\author{
Hongwen Sun',Yanfeng Zhang, Peng Zhang,Ting Wang, Shigenori Morita, Hirotaka Matsuda \\ 'Corresponding Author \\ College of Environmental Science and Engineering, Nankai University, Tianjin 30007I, China \\ Email: sunhongwen@nankai.edu.cn
}

ABSTRACT: To improve the recycling of agricultural biomass residues in China, the present project surveyed the recycling patterns of agricultural waste biomass in Japan via literature review and field visits. The state of agricultural straw recycling in Tianjin suburb, China was also investigated as a case study. Biochar, as a new approach to the recycling of straw, was studied systematically to explain its possible effects on plant growth, soil microflora, and the fate of several pollutants. To disseminate the advanced strategies and technologies in biomass recycling, a monograph entitled "Biochar and Environment" will be published. As part of the project, a workshop was held and a website was constructed (http://www.shengwutan.org). In Japan there is a long history of good practice of reusing agricultural and other biomass residues, such as wood chips, to generate energy and fertilise soil. In Tianjin, the recycling of agricultural biomass residues has progressed significantly. However, the reuse rate still remains low and techniques are lagging. The study on biochar found that it could promote the growth of wheat and vegetables and immobilise heavy metals and polycyclic aromatic hydrocarbons (PAHs). Moreover, as biochar could influence the hydrolysis and biodegradation of pesticides with varying impacts dependent on its structure, it could be used for pesticide pollution control.

KEYWORDS: agricultural straw, biomass recycling, biochar, pollution control, promotion on plant growth 


\section{Project Objectives}

The aim of the project was to transfer the advanced experience in recycling agricultural straw residues from Japan to China. The project will help solve the problems in global climate change, fossil energy crisis and agricultural solid waste treatment, promoting sustainable development in the region. The objectives were to 1) find the best scheme on the recycling of agricultural straw for China; 2) disseminate selected advanced Japanese strategies and techniques to Chinese decision makers, scientists and farmers to raise their awareness; and 3) build capacity of Chinese scientists to build capacity to conduct innovative studies on biomass reuse.

\section{Innovative Research on Biochar}

Biochar was synthesised from different kinds of agricultural biomass waste, such as the straw of wheat, rice and maize, as well as pig manure, and their properties were characterised (Figure 1). The influence of biochar on soil enzyme, plant growth and nutrition species, and the fate of several pollutants (heavy metals, PAHs and pesticides) were also studied. Biochar is composed of organic and inorganic moieties with a highly porous structure, and its properties, such as pore structure, aromaticity, and polarity vary with raw

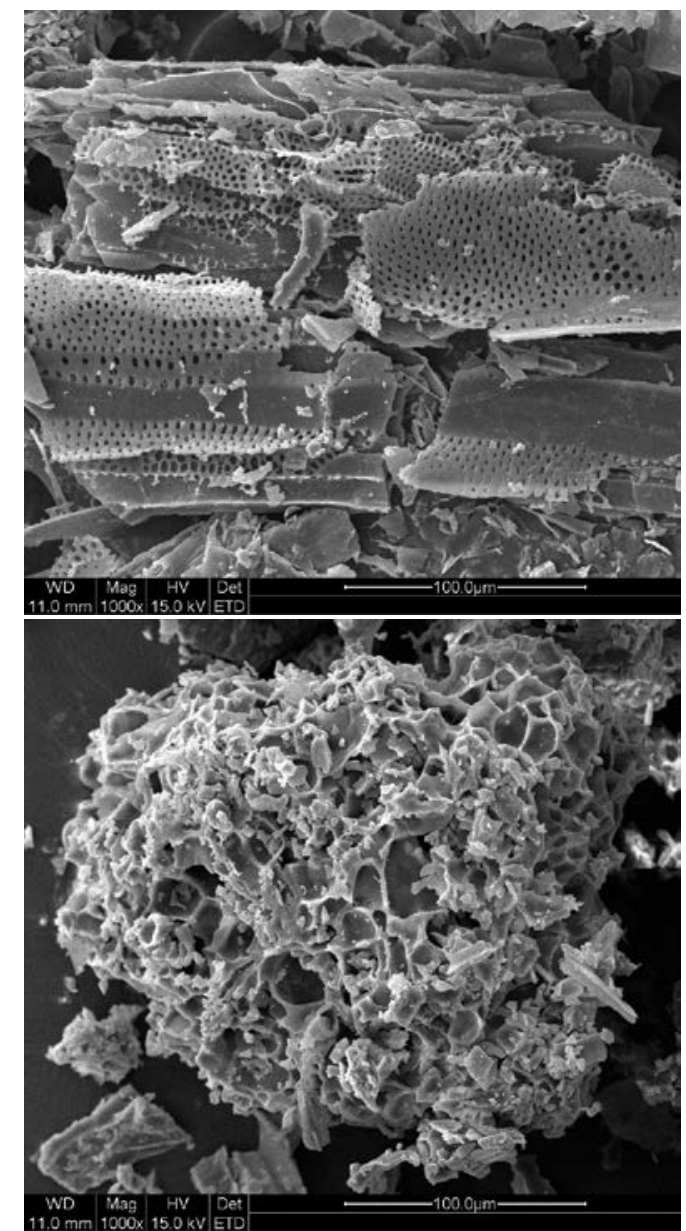

Figure 1. SEM photography of biochars (Top: corn biochar; Bottom: pig manure biochar $\times 5000)$.

material and pyrolysis temperature. Generally, biochar can enhance the growth of wheat and vegetables (Figure 2). In addition, biochar can reduce the availability

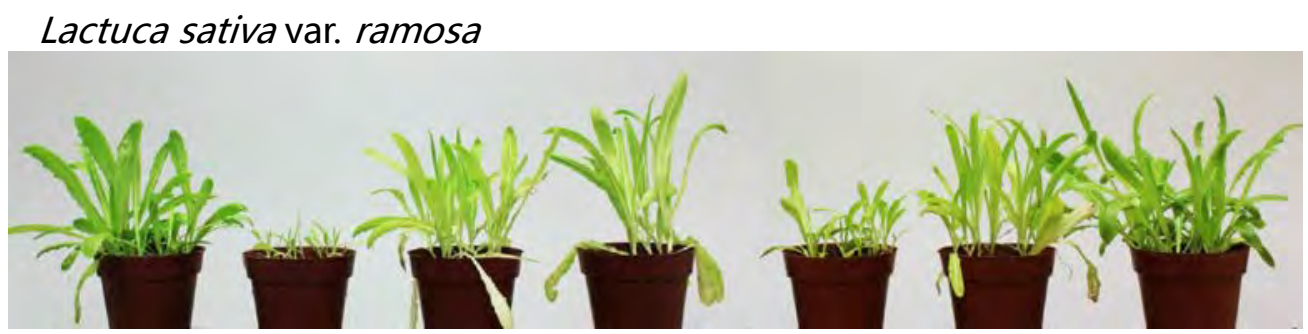

Figure 2. Vegetable growth in soils amended with straw and biochar.

CK; Corn straw; Corn biochar; Corn biochar $+N$; Wheat straw; Wheat biochar; Wheat biochar $+\mathrm{N}$

\section{Amaranthus mangostanus $L$.}

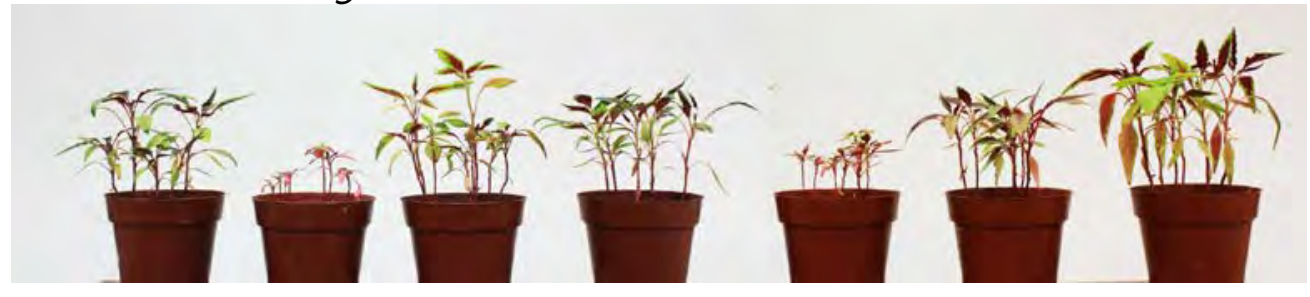

CK; Corn straw; Corn biochar; Corn biochar+N; Wheat straw; Wheat biochar; Wheat biochar $+\mathrm{N}$ 
Figure 3. Project members visiting the farm at Hokkaido University.

Figure 4. Workshop on "Biochar and Enuironment." of heavy metals and PAHs by adsorption, consequently reducing the risk of these pollutants. The influence of biochar on the fate of pesticides is complex, with several processes occurring simultaneously: adsorption, catalysed hydrolysis and enhanced or inhibited (dependent on the type of biochar) biodegradation. The research results provide valuable information for the manipulation of pesticide control.
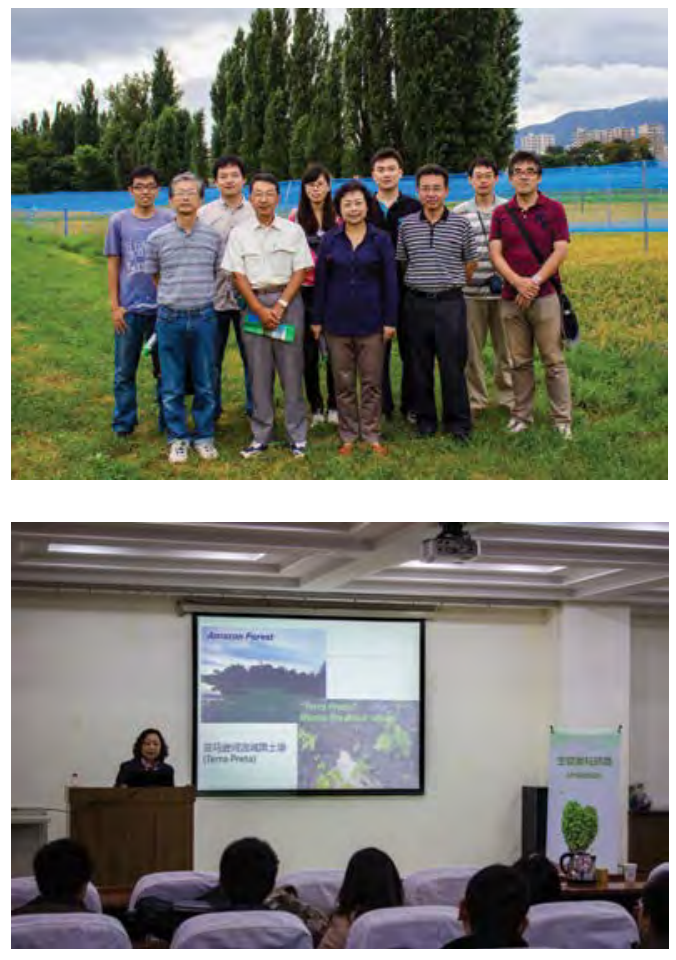

Investigation into the Current State of Agricultural Waste Biomass Recycling in Tianjin

Based on statistical data in 2011, it was estimated that approximately 2,000,000 metric tons of agricultural straw was generated in Tianjin suburb. Currently, about $70 \%$ of the waste straw is reutilised, mainly as fertiliser, feed, base for producing edible fungi, and raw material for producing paper. In some towns, agricultural straws are not recognised as a resource but only as a waste; hence the knowledge dissemination on recycling this resource should be strengthened. There is also a need to further diversify the utilisation patterns of waste straw and to strengthen the conversion of biomass into energy.

\section{Field Visits}

In September 2012, we visited Hokkaido and Tokyo to investigate the reutilisation of biomass and biochar in Japan, accompanied by Professor Morita and Professor Matsuda, the Japanese members of this project. The following visits were made:

1. An experimental farm at Hokkaido University, where there were several devices for biomass waste recycling. For example, a pellet fuel was produced from tomato stems, which could be burnt to generate heat;

2. The Recycling Center of Furano City in northern Hokkaido. Reusable materials, such as bottles, metals, and worn clothing, were separated from the solid waste for reuse. The remnants that could not be recycled were pressed into solid fuel;

3. Shimokawa, a town in northern Hokkaido, where there are large areas of forests and plenty of biomass resources. We visited some facilities that burn wood for power and heating, and a factory that produces charcoal and biochar from woody biomass; and

4. An experimental farm at The University of Tokyo, where we investigated research on producing alcohol from plants for energy (Figure 3).

\section{Dissemination Activities}

A workshop on "Biochar and Environment" was held on 13 April 2013 (Figure 4). Over sixty participants (farmers, students, government officers and participants from the private sector) took part in the workshop and Prof. Sun gave a presentation and disseminated workshop material. A website, which was created to expand dissemination and increase awareness on biochar (www.shengwutan. icoc.cc, in Chinese), was also highlighted.

\section{Project Publications}

A monograph titled "Biochar and Environment" in Chinese is being edited by the publisher and will be published by Chemical Engineering Publisher, China. Several journal papers have been published 
or are under preparation:

Li, L., Lu, Y., Liu, Y., Sun, H., \& Liang, Z. (2012). Study on the adsorption mechanisms of Cd (II) by corn straw biochar. Journal of Agro-Environment Science, 31(11), 2277-2283.

Zhang, P., Sun, H., Yu, L., \& Sun, T. (2013). Adsorption and catalytic hydrolysis of carbaryl and atrazine on pig manurederived biochars: impact of structural properties of biochars. Journal of hazardous materials, 244-245, 217-224. doi:10.1016/j.jhazmat.2012.11.046

Zhang, P., Wu, J., Li, L., Liu, Y., Sun, H., \& Sun, T. (2012). Sorption and catalytic hydrolysis of carbaryl on pig-manure-derived biochar. Journal of Agro-Environment Science, 31(2), 416-421.

Zhang, W., Sun, H., \& Wang, L. (2013). Influence of the interactions between black carbon and soil constituents on the sorption of pyrene. Soil and Sediment Contamination: An International Journal, 22(4), 469-482. doi:10.1080/15320383.2 013.733442

Sun, H. (n.d.). Effect of biochar and straw on plant productivity tissue and soil nitrogen nutrient status. Under preparation.

\section{Acknowledgments}

The authors wish to pay their due gratitude to the Asia-Pacific Network for Global Change Research.

\section{References}

Beesley, L., Moreno-Jiménez, E., \& Gomez-Eyles, J. L. (2010). Effects of biochar and greenwaste compost amendments on mobility, bioavailability and toxicity of inorganic and organic contaminants in a multi-element polluted soil. Environmental pollution (Barking, Essex: 1987), 158(6), 2282-2287. doi:10.1016/j.envpol.2010.02.003

Jablonowski, N. D., Borchard, N., Zajkoska, P., Fernández-Bayo, J. D., Martinazzo, R., Berns, A. E., \& Burauel, P. (2013). Biochar-mediated [14C]atrazine mineralization in atrazine-adapted soils from Belgium and Brazil. Journal of agricultural and food chemistry, 61(3), 512-516. doi:10.1021/jf303957a

Lehmann, J. (2007). A handful of carbon. Nature, 447(7141), 143-144. doi:10.1038/447143a

Marris, E. (2006). Putting the carbon back: Black is the new green. Nature, 442, 442(7103, 7103), 624, 624-626.

Song, Y., Wang, F., Bian, Y., Kengara, F. O., Jia, M., Xie, Z., \& Jiang, X. (2012). Bioavailability assessment of hexachlorobenzene in soil as affected by wheat straw biochar. Journal of hazardous materials, 217-218, 391-397. doi:10.1016/j. jhazmat.2012.03.055

\section{RUSD2011-01CMY(C)-SUN}

\section{PROJECT TITLE}

Assessment and Promotion of
Japanese Strategies and Techniques for
Biomass Recycling in Countryside of
China - Concentrating on Agricultural
Straw Residues

\section{COUNTRIES INVOLVED}

China, Japan

\section{PROJECT DURATION}

2 years

\section{APN FUNDING}

US\$ 55,000

\section{PROJECT LEADER}

Prof. Hongwen SUN

College of Environmental Science and Engineering, Nankai University, Tianjin 300071, China

\section{Tel: +8622 23509241}

Email: sunhongwen@nankai.edu.cn

Website: http://env.nankai.edu.cn

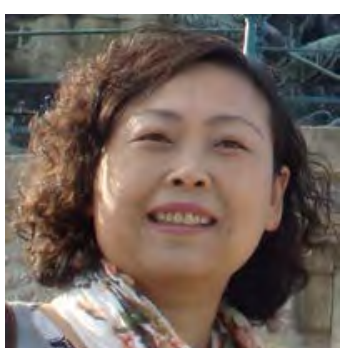




\section{Advancing Local Green Practices Towards Establishing Sound Material Cycle Society in Asian Cities}

Akhilesh Surjan', Manmohan Kapshe, Tran Huu Tuan and Ika Dewi Ana

'Corresponding Author

Kyoto University and United Nations University, Japan

Email:surjan@unu.edu

ABSTRACT: "Sound Material Cycle (SMC) Society" and "Material Flow" both largely remain an alien concept for most cities of Asia's developing countries, which routinely struggle to manage increasing daily waste within their municipal limits. However, the huge populace fuelling the growth of these cities has its own frugal ways and modest means which have catapulted them to the top spot in the world's Green Index (study conducted by the National Geographic), making them the most environmental-friendly denizens of Planet Earth. To arrest this diverse reality, this multi-country research reviews urban expansion and analysis of lifestyles to ascertain changing material flows in domestic sectors as well as prevailing reuse and recycle practices, which may be considered as a precursor to the idea of establishing a SMC Society. Further, field realities from the selected cities of India, Indonesia, Viet Nam as well as Japan are being captured to arrest miniscule and oft-ignored dimensions of cyclicity of the materials at the household, community and city levels. Descriptive, qualitative and technical analysis of selected key material sectors (such as construction, packaging, automobiles, consumer electronics, etc.) of these case-study cities is helping to establish that cities are ideal candidates for promoting SMS pathways.

KEYWORDS: reduce, reuse, recycle, material cycle, green-practices, urban areas 


\section{Project Objectives}

This study aimed at supplementing ongoing Japanese efforts to establish SMC Society (including 3R and Material Flows) in Asia while highlighting three unique elements for success; [i] Urban systems (because urban areas contribute to over two-thirds of the region's GDP); [ii] Green local practices (because communities are "key to success of SMC Society"); and [iii] Partnerships (because local government, NGOs, communities and academia must work hand-in-hand with SMC experts). The specific objectives include: (a) Stimulate multidisciplinary, context-based and community-centred basic ingredients for advancing SMC-Society vision in selected countries of Asia; (b) Substantiate scientific SMC research by combining inputs from natural and social science practitioners to demonstrate that SMC can help urban regions to achieve waste reduction/resource efficiency, move towards low carbon society and reduce pollution; (c) Identify, analyse and document "modest, frugal and green living practices" of citizens, find the challenges to these practices and revitalise them by participatory mechanisms and integratin them with SMC approaches in selected case study cities of Asia; and (d) Promote interaction and interest of "local academia-government-NGOsbusinesses-citizens" in SMC by organising consultation meetings, providing better scientific information, sharing perspectives from Japan and progress from other case study areas for knowledge sharing/mutual learning, and thereby gradually influencing national and regional policies.

\section{Work Undertaken and Results to Date}

This study is progressing through collaboration with local universities in India, Indonesia and Viet Nam. It was decided that the study should focus on the methods of segregating and regulating waste disposal. Attempts were made to document the possible practices that help in reducing the generation of waste. It was discussed that contribution of formal as well as informal processes shall be documented. Towards this, seven material categories of waste are documented in four stages from six sources. Overall material cycle will be analysed in these key-material sectors in selected case-study cities; textile, metal, glass, plastic, paper, biodegradable waste (including food, kitchen and garden waste) and e-waste. The documentation is carried out through these stages: generation of waste, reuse of waste, recycling of waste and disposing of waste. The study will document the generation of waste from six different sources including (1) household; (2) commercial and office establishments; (3) industrial waste; (4) hospital waste; (5) construction waste; and (6) waste from public/semi-public areas. Country-specific progress is as follows:

India: A pilot survey was carried out on households representing five income groups of Bhopal city. It has been observed that textile, plastic, metal, glass, paper and kitchen waste are predominantly generated

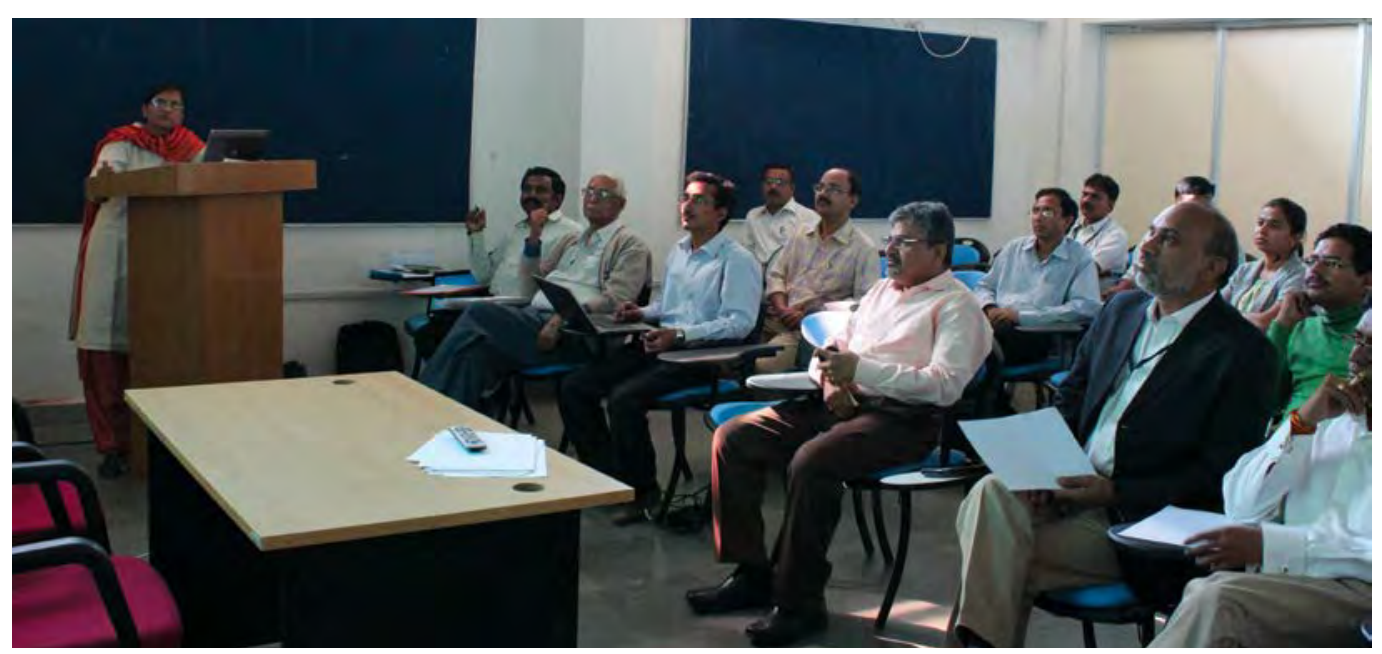

Figure 1. Focus group discussion on local green practices. 

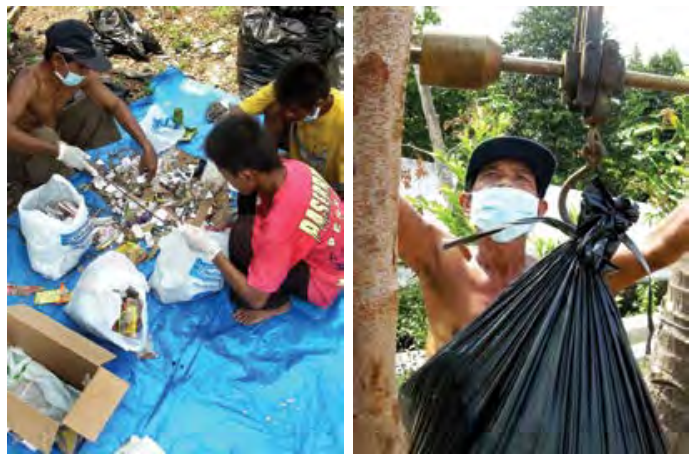

and majority of the waste segregated at household level. Door-to-door waste is regularly collected by Bhopal Municipal Corporation at the household level. Some of the practices used are very common in most of the Indian households while some practices are very rarely used. In addition, a focus group discussion was also held to further engage opinions from various stakeholders. Their views were taken into account to refine some of the pilot study survey questions.

Viet Nam: This study based in Hue city used a mixed data gathering methods in order to collect a robust dataset, including (a) secondary data collection; (b) key informant interviews (KIIs); (c) focus group discussions (FDGs) and meetings; and (d) a consultation workshop. In addition, a documentary film about locally-based green practices in the study area was made. Results from interviewed households show that, on average, each household generates about $3 \mathrm{~kg}$ of waste per day. Review of locallybased green practices showed that the city already has existing models to help reduce
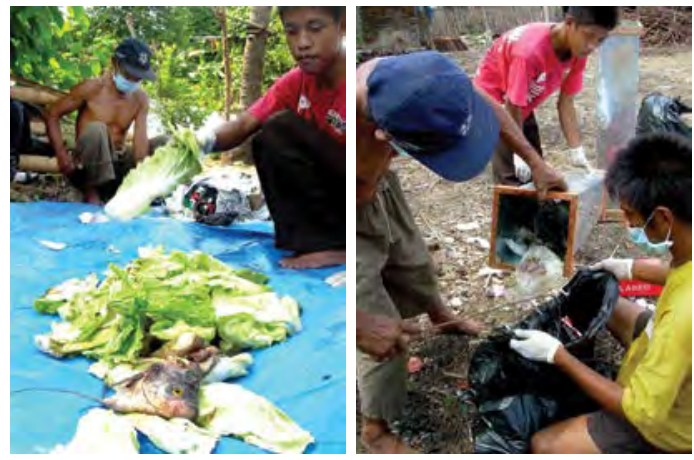

the generation of waste. For example, the existence of informal sectors such as waste pickers, junk buyers and waste collectors involved in collection and recycling of waste shows that their work significantly reduces in amount of waste; it reduces a large amount of landfill for the city. In addition, it eliminates much of the costs associated with the transport, treatment and burying of waste.

Indonesia: Survey in Yogyakarta, a case study city, reveals that most volume of waste material is organic waste that is mainly produced by the construction and agriculture sectors. Since 2008, the local government has been trying to reduce the waste transported for final disposal. The new method involves the $3 \mathrm{R}$ practices. The "new paradigm" is based on the fact that their facility cannot transport all waste in Yogyakarta. In 2009, the government supported $3 \mathrm{R}$ practices by giving 150 composters in the river plain communities and 90 composters in all 45 sub-districts.

\section{RUSD2011-02CMY(R)-SURJAN}

\section{PROJECT TITLE}

\section{Advancing Locally-based Green \\ Practices to Realise Establishment of Sound Material Cycle Society in Asian Cities}

\section{COUNTRIES INVOLVED}

India, Indonesia, Japan, Viet Nam

PROJECT DURATION

3 years

\section{APN FUNDING}

US\$ 120,000

\section{PROJECT LEADER}

Dr. Akhilesh SURJAN

Inter-Graduate School Program for Sustainable Development and Survivable Societies (GSS), Kyoto University, Centro Culturale Italo Giapponese di Kyoto, 4 Ushinomiya-cho, Yoshida, Sakyo-ku, Kyoto 606-8302, Japan

Tel: +8175 5857202

Email: surjan@unu.edu

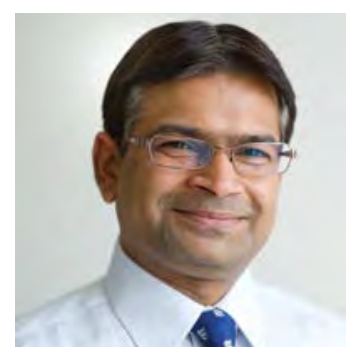




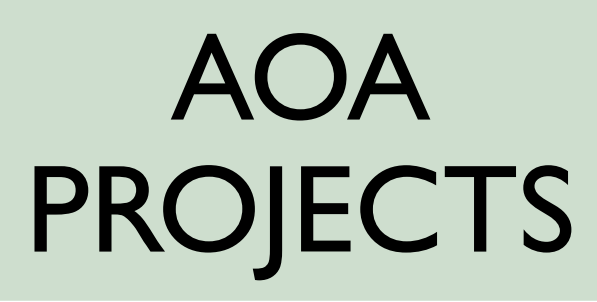

AOA Projects:

\section{Other Activities Endorsed by the Inter-Governmental Meeting (IGM)}




\title{
Towards Low Carbon Development and Transition in Asia
}

\author{
Takako Wakiyama', Shuzo Nishioka,Tomoko Ishikawa \\ 'Corresponding Author \\ Institute for Global Environmental Strategies, Japan \\ Email:wakiyama@iges.or.jp
}

\begin{abstract}
LoCARNet is a network of researchers that facilitates the formulation and implementation of science-based policies for low carbon development in Asia. It was launched in 2011 as a knowledge-sharing network of researchers deeply involved in domestic policy-making processes and aware of the importance of facilitating the realisation of a low carbon sustainable society. From its initiation, LoCARNet has facilitated science-based policies in order to realise a sustainable future with a stabilised climate. To this end, the network endeavours to establish research capacity in the region based on south-south-north cooperation and reflect research findings into policies to achieve low carbon growth. So far, LoCARNet has supported researchers and policy makers in Asia across different countries and sectors, facilitating their involvement in activities and furthering their capacity development. LoCARNet is expected to extend its activities to a worldwide research network to enhance south-south-north collaboration and provide practical input to the UNFCCC and the IPCC.
\end{abstract}

KEYWORDS: low carbon societies, science-policy, knowledge sharing 


\section{Background Information}

APN's Low Carbon Initiatives Framework was launched in 2012 to promote research activities within developing countries in the Asia-Pacific region by providing support for these countries to form scenarios towards low carbon societies, as well as to identify policies to realise low carbon development, in light of the increasing importance of this region as it expected to become one of the leading areas in the world in terms of low carbon development. This programme has supported the activities of the Low Carbon Asia Research Network (LoCARNet) since its initiation.

LoCARNet is a network of researchers that facilitates the formulation and implementation of science-based policies for low carbon development in Asia. It was launched in 2011 as a knowledge-sharing network of researchers who are deeply involved in domestic policymaking processes and are aware of the importance to facilitate the realisation of a low carbon, sustainable society. Therefore, the aim of LoCARNet is to facilitate science-based policies in order to realise a sustainable future with a stabilised climate. To this end, the network endeavours to establish research capacity in the region based on south-south-north cooperation and to reflect research findings into policies to achieve low carbon growth.

\section{Low Carbon Growth Policy Research}

While Asian countries have common challenges and issues related to climate change, their culture (lifestyle, consumption patterns and social norms), geographical situations, areas of focus for GHG emission reduction activities and their concerns differ along with each country's particular economic state and development path. Moreover, emission factors and human and technical capacities differ in each country. It is widely accepted that low carbon growth research requires broad disciplinary knowledge, tools and methods for successful integration into the practical policy process. Against this backdrop, LoCARNet plays an important role in enhancing communications across different sectors and stakeholders through dialogue, information-sharing and joint studies. LoCARNet has efficiently promoted research for policies towards low carbon growth by enabling sufficient dialogue between scientists and policy makers while also encouraging collaboration amongst in-country researchers, whose research capacity and scientific knowledge are firmly grounded in their home countries.

The procedures associated with the formulation and execution of low carbon growth policy are target setting, policy planning, selection of policies using economic and social evaluation, policy implementation, monitoring the effects of policies, and revising policies through review and feedback processes. Various urgent issues have been raised by the research community and policy makers and the importance of low carbon research has been highlighted, including the policy-making process and the use of integrated assessment models (IAMs); land use and forestry; GHG inventories; low carbon cities; local level practices, decisions and initiatives; the institutionalisation of low carbon green growth; and technology.

When formulating low carbon policies, policy options for climate change mitigation must be assessed. The suitability of the enabling policy options should be confirmed from various facets using scientific analysis, including both basic and advanced research. At the policy planning stage, for example, research requirements include data collection, formulation of a GHG inventory, technology needs assessments and IAM application. LoCARNet collaborates with the Asian Integrated Model (AIM) team at the National Institute of Environmental Studies (NIES) in Japan and with other researchers in Asia to formulate low carbon scenarios and create low carbon roadmaps as initial steps for developing low carbon societies in Asia.

Dialogues and workshops conducted between researchers and policy makers suggest that Asian countries have advanced their climate change mitigation activities, including the establishment of climate change policies and strategies, while also developing their research capacity. Numerous countries have integrated climate change issues into their national development plans in order to tackle climate change; this itself is a reflection of mainstreaming climate change mitigation measures. However, some countries need to develop research capacity and policy plans, while some have made efforts to set up national targets for climate change mitigation and submitted their National Appropriate Mitigation Actions (NAMAs) to the UNFCCC.

Knowledge platforms such as LoCARNet serves an important function as further backup support for developing and implementing low carbon policy towards 2014, 2020 and 2050. As its next step, LoCARNet is working to extend its activities to a worldwide research network to enhance south-south-north collaboration and produce practical inputs to UNFCCC negotiations and the IPCC. Therefore, LoCARNet will continue its collaboration with other organisations and provide a platform to share knowledge and experiences, not only throughout Asia but beyond. 


\section{First LoCARNet Annual Meeting}

The first annual meeting of the Low Carbon Asia Research Network (LoCARNet) was held in Bangkok, Thailand, 16-17 October 2012, co-organized by IGES (LoCARNet Secretariat), Asian Development Bank (ADB), APN, Joint Graduate School of Energy and Environment (JGSEE), Ministry of the Environment of Japan (MOEJ) and Thai Greenhouse Gas Management Organization (TGO).

At the opening session, Mr. Spachai Watanangura, Board of Directors of TGO and Mr. Soichiro Seki, Director General of Global Environment Bureau of MOEJ made statements and acknowledged the APN for its financial support to LoCARNet. Dr. Shuzo Nishioka, Secretary General of LoCARNet introduced the background, possible activities and his ideas on the way forward.

Following the opening session, a series of breakout sessions were held on a variety themes, including IAMs, land use and forestry, greenhouse gas inventories, low carbon cities, local level initiatives, green growth and technology.

In Day 2, a dialogue between researchers and policy makers was held to discuss sciencepolicy interaction, followed by another dialogue with stakeholders for discussing how LoCARNet will network with relevant organisations and what LoCARNet will do in the future. Dr. Akio Takemoto, Director of the APN Secretariat, participated in the panel discussion of this dialogue and introduced the APN and its LCI Framework, a new APN programme to support regional research and capacity building activities in member countries. Drawing experience learned from the 16-year history of APN, he suggested LoCARNet develop a strategic plan that includes a common vision, mission and action plan in order to promote and sustain LoCARNet. He also suggested that LoCARNet develop partnerships with other organisations and networks to create mutual benefits.

At the wrap-up session, the LoCARNet Secretariat summarized key findings and concluded that these findings would be incorporated into the action plan of the LoCARNet.

\section{Project Publications}

LCS-RNet Secretariat. (2010). Towards sustainable low-carbon development and green growth in Indonesia and Asia-Linking research and policy (synthesis report). Institute for Global Environmental Strategies (IGES). Retrieved from http://lcs-rnet.org/publications/ pdf/2010BogorSynthesisReport.pdf

LCS-RNet Secretariat. (2011a). Synthesis report of scientific approach to low carbon development planning in Cambodia: Stakeholders' dialogue on the Cambodian low-carbon development research need. Institute for Global Environmental Strategies (IGES). Retrieved from http://lcs-rnet.org/
Figure 1. Participants at the First LoCARNet Annual Meeting.

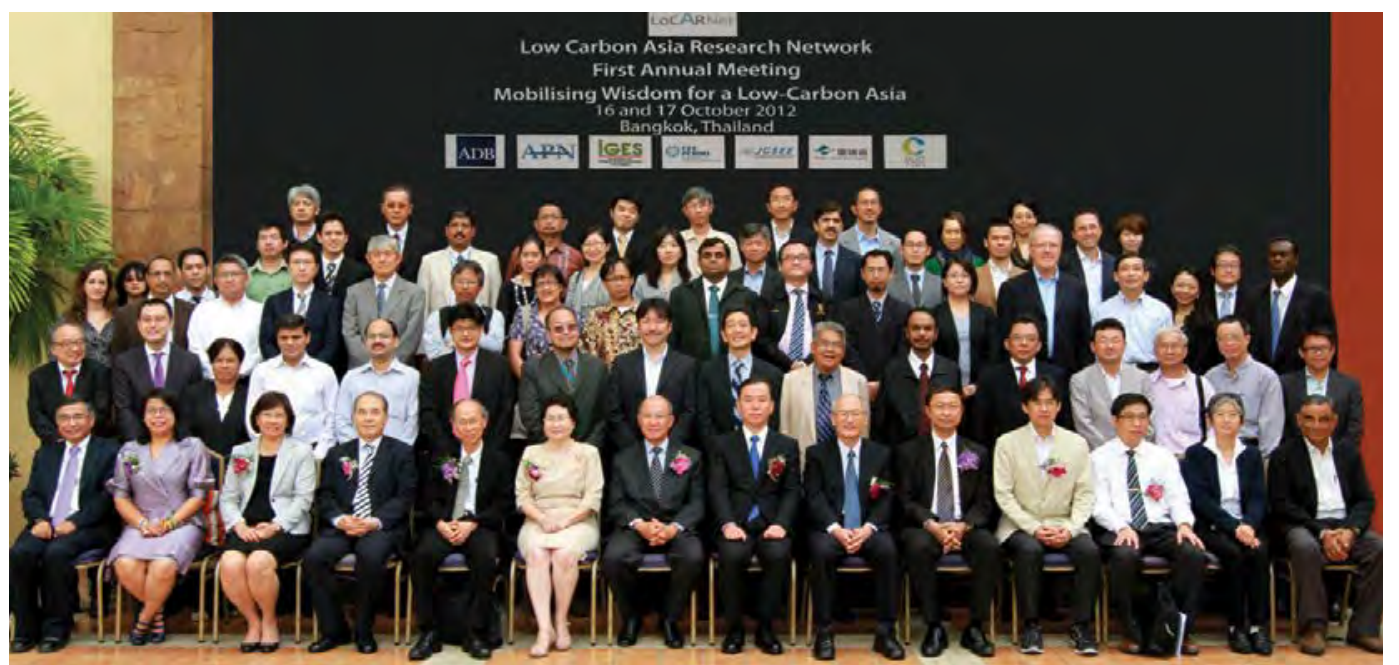


publications/pdf/LCS-RNet_Cambodia_Synthesis. pdf

LCS-RNet Secretariat. (2011b). Synthesis report of transition towards low carbon societies in Thailand and Asia-Dialogue between policy-makers and researchers and cross-sectoral approach. Institute for Global Environmental Strategies (IGES). Retrieved from http://lcs-rnet.org/publications/ pdf/2011SynthesisReport_Thailand.pdf

LCS-RNet Secretariat. (2012). A low-carbon Asia: From Malaysia to Asia: Dialogues between Policy-makers and researchers: Towards implementation (Synthesis Report). Institute for Global Environmental Strategies (IGES). Retrieved from http://lcs-rnet. org/publications/pdf/201203_malaysia.pdf

LoCARNet Secretariat. (2012a). Mobilising wisdom for a low-carbon Asia: Synthesis report of LoCARNet First Annual Meeting 2012 (synthesis report). Institute for Global Environmental Strategies (IGES). Retrieved from http://lcs-rnet.org/publications/ pdf/2012_LoCARNet_1st\%20Annual\%20Meeting Synthesis\%20Report.pdf

LoCARNet Secretariat. (2012b, November). LoCARNet Newsletter Volume 1. Retrieved from http://lcs-rnet. org/publications/pdf/LoCARNet_Newsletter_Voll. pdf

LoCARNet Secretariat. (2013). Designing and establishing Cambodian low-carbon development plan: Cambodia workshop 2012 (Synthesis Report). Hayama: Institute for Global Environmental Strategies (IGES). Retrieved from http://lcs-rnet. org/publications/pdf/Cambodian\%20report2012. pdf

\section{References}

Japanese Cabinet. (2008, July 29). Action Plan for achieving a low-carbon society. Retrieved from http://www.kantei.go.jp/foreign/policy/ondanka/ final080729.pdf

LCS-RNet Secretariat. (2010). Introduction to low carbon societies: The challenges for an international research network for low carbon societies. Institute for Global Environmental Strategies (IGES). Retrieved from http://lcs-rnet.org/pdf/LCS-RnetBro_EN.pdf

LoCARNet Secretariat. (n.d.). About LoCARNet. Retrieved July 2, 2013, from http://lcs-rnet.org/ about_locarnet.html

Low-Carbon Asia Research Project. (n.d.). Low-carbon society research project. Retrieved July 2, 2013, from http://2050.nies.go.jp/

Ministry of the Environment, Japan. (2007, December). Building a low carbon society: First draft. Retrieved from http://www.env.go.jp/earth/info/pc071211/ en.pdf

Nishioka, S. (2012). LoCARNet presentation. Retrieved from http://www.iges.or.jp/en/news/topic/ pdf/1211cop18/Shuzo_Nishioka.pdf

\section{AOA2012-02NSY-NISHIOKA}

\section{PROJECT TITLE}

First Annual Meeting of LoCARNet, Bangkok, Thailand, 16-17 October 2012

\section{COUNTRIES INVOLVED}

LoCARNet Member Countries

\section{DURATION}

1 year

\section{APN FUNDING}

US\$ 40,000

\section{PROJECT LEADER}

\section{Shuzo NISHIOKA}

LCS-RNet/LoCARNet Secretariat

c/o Institute for Global Environmental Strategies (IGES)

2108-11 Kamiyamaguchi, Hayama, Kanagawa 2400115, Japan

Tel: +81 468553809

Email: Ics-rnet@iges.or.jp

Website: http://lcs-rnet.org/index.html

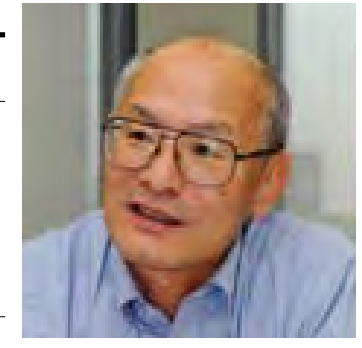

\section{.}




\title{
Future Earth in Asia and the Pacific
}

\author{
Nordin Hasan' \\ 'Corresponding Author \\ ICSU Regional Office for Asia and the Pacific, 902-4, Jalan Tun Ismail, 50480 Kuala Lumpur, Malaysia \\ Email: nordin.hasan@icsu-asia-pacific.org
}

ABSTRACT: Future Earth is a 10-year international programme on Earth system research for global sustainability. The goal of Future Earth is to provide the knowledge required for societies in the world to face risks posed by global environmental change and seize opportunities in a transition to sustainability. While the scope of Future Earth is global, a number of issues requires region-specific approaches. The Future Earth Regional Workshop for Asia and the Pacific was organised as a first step to look at a regional approach for Future Earth and as part of a broader consultation process. The workshop was effective in building an understanding of Future Earth among participants, providing information on current initiatives and developing a common vision for Future Earth in the region. The key recommendations made at the workshop refer to the coordination and convergence of activities under Future Earth. These include the needed learning and capacity development initiatives, and elements of science-policy and stakeholder interfaces required to make Future Earth a success. The Asia-Pacific region has the capacity to drive the transition towards global sustainability under the Future Earth programme. Its scientific community is ready to make the change to support integrated research that can build new ways to engage developed and less developed countries and help ensure socially-inclusive and environmentally-sound development.

KEYWORDS: Future Earth, global environmental change, coordination and convergence, capacity development, science-policy and stakeholder interfaces 


\section{HIGHLIGHTS}

» Future Earth is an international programme on Earth system research for global sustainability which aims to provide the knowledge required for societies in the world to face risks posed by global environmental change and to seize opportunities in a transition to global sustainability.

» The Future Earth RegionalWorkshop for Asia and the Pacific provided specific recommendations on coordination and convergence of activities and initiatives; learning and capacity development needs; and science-policy and stakeholder interfaces required to make Future Earth a success.

» The Asia-Pacific region has the ability to lead the move towards global sustainability under the Future Earth programme. Its scientific community is ready to make the change to support integrated research that would build the knowledge and solutions necessary for the transition to sustainability.

\section{Introduction}

Future Earth is a 10-year international programme on Earth system research for global sustainability that was launched in June 2012 at the United Nations Conference on Sustainable Development (Rio+20). It will provide critical knowledge required for societies in the world to face risks posed by global environmental change and to seize opportunities in a transition to global sustainability.

Future Earth aims to build on, and augment, the Earth system science capabilities developed over the last few decades by incorporating research on the impacts of environmental change on people, developing and assessing strategies for response, and developing models of adaptation and transformation. It will engage a broader range of natural and social science disciplines so that the international research community can take the next critical steps in providing the knowledge needed. It also recognises that research needs to be co-designed with governments, industry and civil society groups if pathways to a sustainable future are to be found.

\section{Connecting Research Responses to Societal Challenges}

Future Earth will address issues critical to poverty alleviation and development such as food, water, energy and human security and the connection between these areas and the overarching imperative of achieving global sustainability. It provides an opportunity to refocus research priorities, open up new research frontiers and establish new ways to produce research in a more integrated and solutions-oriented way.

Future Earth will integrate and build on the strength of existing Global Environmental Change (GEC) programmes - the World Climate Research Programme (WCRP), the International Geosphere-Biosphere Programme (IGBP), the International Human Dimensions Programme (IHDP), DIVERSITAS and the Earth System Science Partnership (ESSP).

Future Earth will be one programme, which promotes co-designing of its research, capacity building and outreach activities by the broad community of researchers including natural, social, engineering and human sciences in partnership with governments, business and stakeholders in order to close the gap between environmental research, policies and practices. It will deliver a step change in making research more useful and accessible for decision makers.

\section{The Conceptual Framework}

The conceptual framework for Future Earth (Figure 1) describes an interconnected system in which both natural systems and human activity are driving changes in the regional and global environment, 
Figure 1. Schematic of the Future Earth conceptual framework.

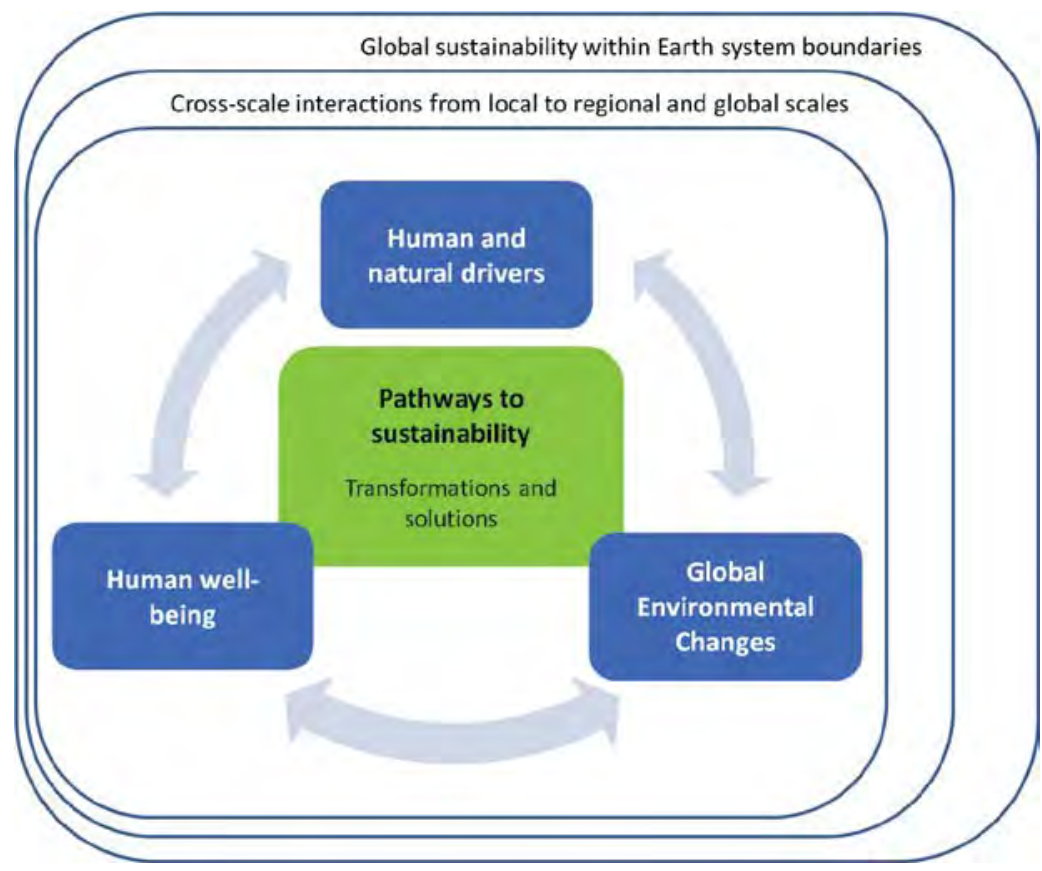

research.

with significant implications for human wellbeing. This fundamental, holistic understanding is the basis for the identification of transformative pathways and solutions for global sustainability.

\section{Future Earth Research Themes}

Future Earth's three research themes will function as broad platforms for integrated earth systems research, which will involve collaborative projects across disciplines that include:

1. Dynamic Planet - understanding how Planet Earth is changing due to natural phenomena and human activities. The emphasis will be on observing, explaining, understanding projecting Earth, environmental and societal system trends, drivers and processes, and their interactions; anticipating global risk thresholds.

2. Global Development - providing the knowledge for sustainable, secure and fair stewardship of biodiversity, food, water, health, energy, materials and other ecosystem services. The emphasis of Future Earth research will be on determining the impacts of human activities and environmental change on the health and wellbeing of people and societies through integrated social-environmental
3. Transformation Toward Sustainability - understanding the transformation processes and options, assessing how these relate to human values, emerging technologies and economic ideas, and evaluating strategies for governing and managing the global environment across sectors and scales. The emphasis of Future Earth research will be on solution-oriented science that enables societal transitions to global sustainability.

These research themes will play the role as major integrating units under Future Earth, each hosting a collection of existing as well as new, co-designed international research projects.

\section{Future Earth Regional Workshop for Asia and the Pacific}

While the scope of Future Earth is global, a number of issues requires region-specific approaches. Regions, as early witnesses of environmental change, have a critical contribution to make in assessing environmental change and to participate in building a global picture for transitioning towards sustainability.

As a first step in looking at a regional approach for Future Earth, a series of regional workshops were held as part of a broader 
consultation process. This consultation process sought to test and refine the initial design proposal with key stakeholders as Future Earth enters its operating phase.

The Future Earth Regional Workshop for Asia and the Pacific was held from 21-23 November 2012 in Kuala Lumpur. It was attended by 51 participants from the Asia-Pacific region, members of the Transition Team and representatives of the Global Environmental Change (GEC) community.

The workshop aimed to develop a common understanding of Future Earth, including its vision, research framework and governance; to identify regional research priorities that will help shape the Future Earth research strategy in the Asia-Pacific region; to discuss opportunities and challenges for implementing Future Earth in the region; and to explore ways of establishing a regional interface for Future Earth.

\section{Key Recommendations from the Regional Workshop}

The Asia-Pacific region has the capacity to drive a transition towards global sustainability under the Future Earth programme. Its scientific community is ready to make the changes needed to support integrated research that would build the knowledge and solutions for the transition to sustainability. Through Future Earth, the region can develop new ways to engage developed and less developed countries and help ensure socially-inclusive and environmentallysound development.

The workshop made the following specific recommendations:

\section{Coordination and convergence}

- Develop an understanding of what sustainability means at the national and regional levels, taking into account varying cultural contexts

- Develop global sustainability indicators that can guide implementation at the regional and sub-regional levels
- Develop strong regional representation in Future Earth and regional priorities that are developed through in-depth, long-term and sustained discussions

- Create alliances of current integrated research projects and researchers upon which to build long-term strength

- Define clear mechanisms, such as an endorsement process, for projects to become part of Future Earth

- Develop incentive mechanisms to promote transdisciplinary research

- Foster networks for scientists across regions, disciplinary fields and stakeholders.

Learning and capacity development

- Compile examples of best practices of transdisciplinary research on sustainability issues beginning with small and local scale projects that could be scaled up through programmes at the regional and national levels

- Document case studies of successful integration and interdisciplinary work in the region and create guidelines on co-design and co-produce research

- Increase human capacity development training programs, through short-term workshops, exchange of graduate students, increasing the number of graduate research positions and Professorial Chairs within countries in the region, and develop mentoring of young scientists in least developed countries by more experienced researchers.

\section{Science-policy and stakeholder interface}

- Develop an understanding of what the points of entry into the policy arena are

- Develop approaches and programmes to bring into dialogue groups of people who do not normally talk to each other 


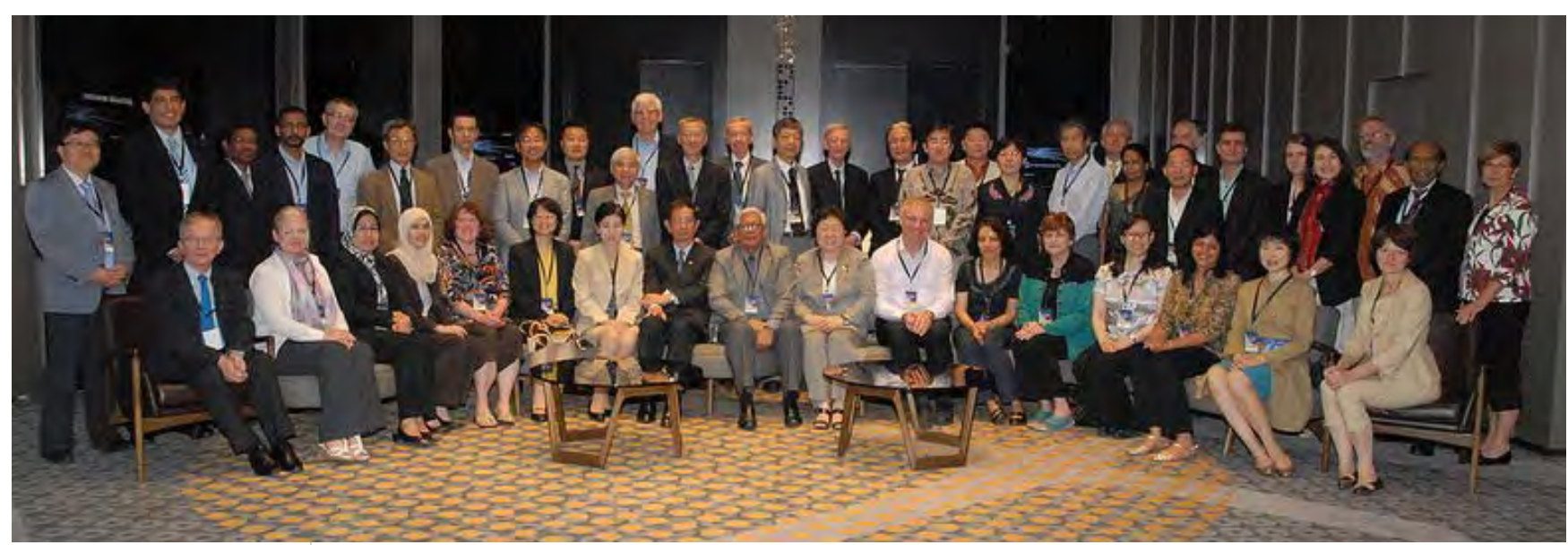

Figure 2.

Participants at the Future Earth Regional Workshop.
- Translate and share models on how to influence policy makers - taking into account the wide range of political systems and cultural settings prevalent in the region - and businesses, and sustain successful science-policy dialogues

- Create or identify science-policy platforms to effectively inform and engage decision and policy makers

- Engage indigenous communities and local knowledge systems in the research process

\section{Way Forward}

The way forward for Future Earth in the Asia-Pacific region will begin by involving existing GEC-related programmes, networks' leaders and their funders in discussions that would enable the establishment of a linkage between the regional Future Earth interface and the governing bodies of Future Earth.

It is also very crucial for a regional plan for the implementation of Future Earth in the Asia-Pacific region to clearly define priority research areas and desired outcomes in the first five years of Future Earth.

The regional component is extremely important for Future Earth, and the Asia-Pacific region has the ability to lead the move towards global sustainability under the Future Earth programme. Through the Future Earth initiative, a new way of doing research will be developed that will connect knowledge about sustainability to effective solutions and actions that can help bring about key transformations to the region that will get our societies on the path to sustainability.

\section{AOA2012-07NSY-ICSU-ROAP}

\section{PROJECT TITLE}

Future Earth Regional Workshop for Asia and the Pacific, Kuala Lumpur, Malaysia, 21-23 November 2012

\section{COUNTRIES INVOLVED}

Australia, China, Fiji, India, Indonesia, Japan, Malaysia, Mongolia, New Zealand, Philippines, Republic of Korea, Sri Lanka, Thailand, USA, Viet Nam

\section{DURATION}

1 year

\section{APN FUNDING}

US\$ 19,400

\section{PROJECT LEADER}

Mohd Nordin HASAN

International Council for Science Regional Office for Asia and the Pacific (ICSU-ROAP) 902-4, Jalan Tun Ismail, 50480 Kuala Lumpur, Malaysia

\section{Tel: +603 26949898}

Email: nordin.hasan@icsu-asia-pacific.org

Website: www.icsu.org/asia-pacific

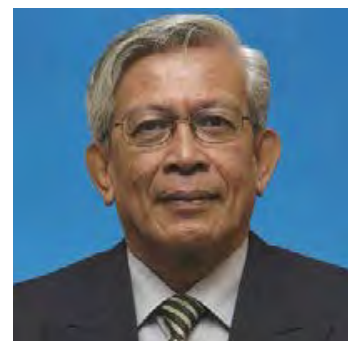




\title{
International Conference on Climate Change Impacts and Adaption for Food and Environmental Security
}

\author{
Felino Lansigan' \\ 'Corresponding Author \\ University of the Philippines Los Baños \\ Email:fplansigan@yahoo.com
}

CONFERENCE BACKGROUND: Climate change and climate variability are among the top issues facing the world today. They pose real threats to the environment and to human systems specifically agricultural production, biodiversity and health, among others. Extreme climatic events such as typhoons are becoming more frequent and destructive, prolonged wet and dry seasons, and increased incidences of disease and pest outbreaks negatively affect agricultural production systems, leading to food and livelihood shortages - consequently threatening food and environmental security. Growing evidence of climate change around the world and in particular Southeast Asia, compels all sectors to act to ensure sustainability of lifelines that include: natural systems and food resources, rural livelihoods and human resources. The Southeast Asian region is challenged to increase its capacities and expertise to attain the set objectives of the Millennium Development Goals (MDGs), specifically those that pertain to eradicating extreme poverty and hunger and ensuring environmental sustainability. However, much of the research on climate change is conducted in a fragmentary fashion in different countries by discipline and sector. This situation presents opportunities for developing multidisciplinary and multisectoral approaches. It is in this regard that the International Conference on Climate Change Impacts and Adaptation for Food and Environmental Security (ICCCIAFES) was proposed to provide a venue for promoting integrative partnerships toward convergence of ideas for holistic solutions to reduce the impacts of climate change on the region's food, environmental, nutritional and health security. 


\section{Objectives}

ICCCIAFES' main goal was to bring together researchers, academicians, policy makers and planners, development workers and other professionals in the region in a discussion forum to exchange information and forge linkages towards enhanced capacity to achieve food, environmental, nutritional and health security in the face of climate change.

Specifically, the conference aimed to:

1. Exchange state-of-the-art knowledge on climate change science, adaptation strategies, disaster risk reduction, planning and management, and vulnerability and impact assessment tools among regional stakeholders specifically in the agriculture and environment sectors;

2. Gather scientific information and experiences into an integrative body of knowledge in order to identify knowledge gaps and common, urgent and emerging issues related to food and environmental security in the region;

3. Identify location-specific knowledge and adaptation strategies that may be upscaled to other regions; and

4. Promote partnerships and linkages among different sectors for collaborative activities on climate change adaptation.

\section{Conference Coverage}

\section{Call for Abstracts}

The conference invited submission of abstracts on the following themes:

- Effects and impacts of climate change on food and environmental security issues, including state-of-the-art knowledge and assessment tools such as vulnerability assessment, risk characterisation, risk analysis, and impact assessment;

- Institutional (policy, governance, culture) and economic aspects of climate change science and adaptation;

- Country and regional collaborative experiences for climate change adaptation and disaster risk reduction; and

- Other climate change-related topics relevant to the conference theme.

\section{Knowledge Partners}

ICCCIAFES was held on 21-22 November 2012 at the Southeast Asian Regional Center for Graduate Study and Research in Agriculture (SEARCA) in Los Baños, Laguna, Philippines. Around 150 researchers, academicians, policy makers, and development workers representing 21 countries participated.

The conference was jointly organised by SEARCA and the University of the

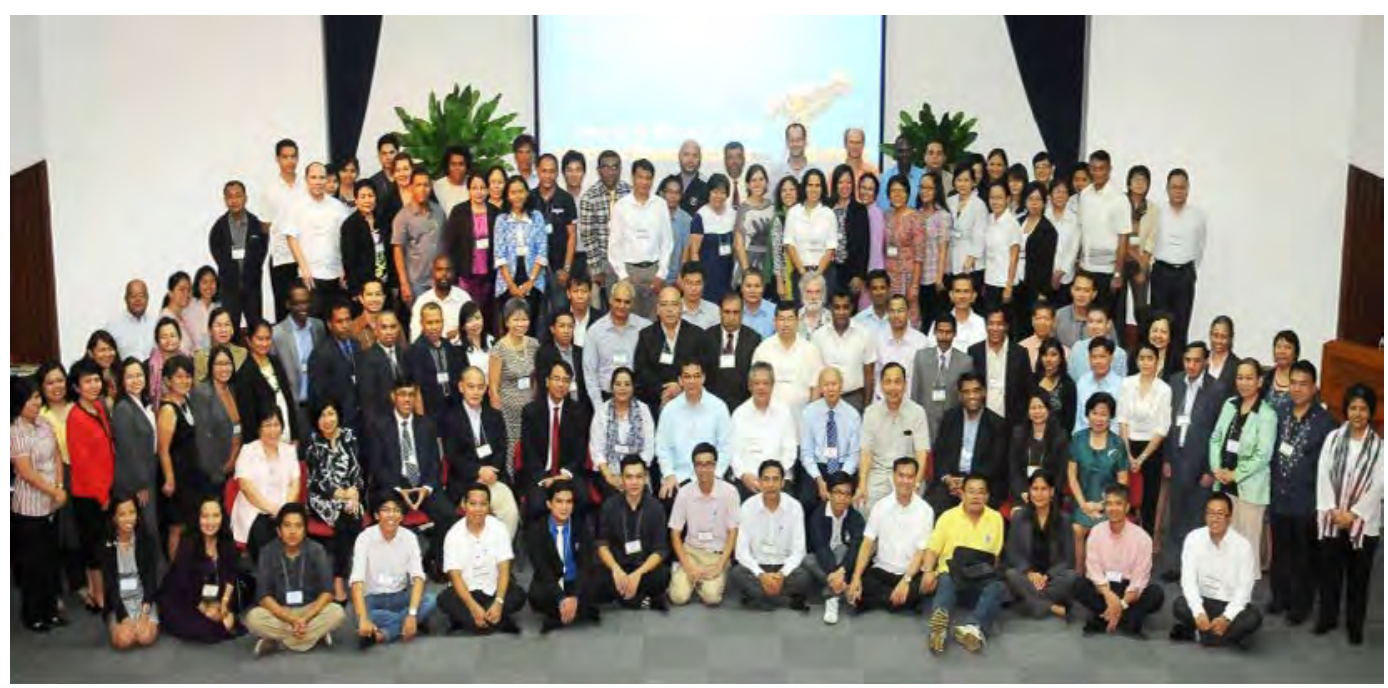

Figure 1. Participants of the conference. 
Philippines Los Baños (UPLB) through its Interdisciplinary Program on Climate Change (IdPCC), with the Asia-Pacific Adaptation Network (APAN), supported by the Institute for Global Environmental Strategies (IGES) in Japan, as the major sponsor. Additional partners included the Asia-Pacific Network for Global Change Research (APN); Food Security Center (FSC) at the University of Hohenheim (UHOH), Germany, and the German Academic Exchange Service (DAAD); Economy and Environment Program for Southeast Asia (EEPSEA); United Nations World Food Programme (UNWFP); and the Philippine Climate Change Commission (PCCC) as supported by the German Agency for International Cooperation (GIZ).

Likewise, the conference benefitted from the contribution of knowledge partners which included the Nanyang Technological University Rajaratnam School of International Studies- Centre for Non-Traditional Security Studies (NTU RSISCNTS); International Crops Research Institute for the Semi-Arid Tropics (ICRISAT); University of Tokyo, GIZ Biodiversity and Climate Change Project; and Philippine Climate Change Adaptation Project (PhilCCAP).

Serving as a platform for exchange on the latest knowledge on climate change impacts and adaptation linked to food security and environmental sustainability, the scientific meeting had three plenary sessions and four parallel sessions where 44 papers were presented based on the following themes:

- Status, Prospects, and Practices on Climate Change Adaptation in Agriculture;

- Climate Change Impacts and Vulnerability;

- Climate Change Adaptation and Agriculture;

- Institutional and Economic Aspects of Climate Change Impacts and Adaptation;

- Systems and Tools for Analysing Climate Change Impacts and Vulnerability;

- Regional and South-South Collaboration in Research and Development; and
1

$\mathrm{t}$ is not climate change per se that should concern us but its short- and long-term impacts on food security.

-Prof. Paul Teng, Dean, Graduate Studies and Professional

Leaning, National Institute of Education, and Senior Fellow on Food Security, S. Rajaratnam School of International Studies, Nanyang

Technological University, Singapore

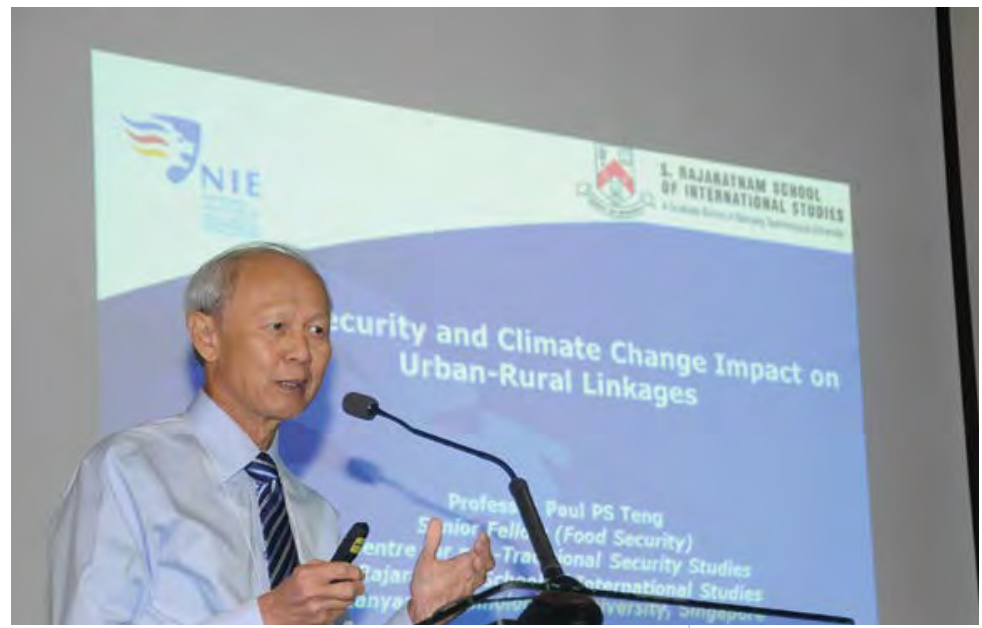

- Networking for R\&D and Capacity Building on Climate Change and Food and Environmental Security.

The papers presented a wide range of new knowledge along with appropriate indigenous or local technologies that can be used to address the impacts of climate change - not only as adaptation strategies - but also for mitigation and increasing resilience. The initiatives described vary widely in methods and approaches: simulation/modelling by experts to highly participatory approaches with direct involvement of end users in the field; differences in ecological zones (tropical forests, agroforestry systems, irrigated lowlands, dryland farms, fish pens in lakes, to pelagic fisheries); and scale (from breeding work/genetic level to household, community up to regional in scope).

The aim was for lessons to be learned, good practices to be adopted or adapted and upscaled, and for new collaborative initiatives to be undertaken so that environmental and food security shall be ensured for the majority of Southeast Asia and other regions that are bearing the brunt of adverse impacts of climate change. 


\section{Conclusion and Recommendations}

The following are the key ideas, findings and lessons from the papers presented in all the plenary and parallel sessions:

1. Climate change is here and now. Rise in temperature, increased climate variability, extreme weather events, etc., clearly pose grave threats to food production, the environment, including lives and property.

2. A wide variety of tools are available to determine the effects of climate change. These tools range from sophisticated simulations and modelling by technical experts (e.g., GIS, SDSM, PRECIS, DSSAT, CORDEX, etc.) to highly participatory approaches involving end users in the local communities (e.g., PRA, documentation of local or indigenous knowledge and practices).

3. Such tools are helpful in pointing to measures needed to mitigate the risks or adapt/improve resilience to the effects or impacts of climate change. These measures need to be implemented in an integrated fashion to be effective, which include a combination of the following factors: change in people's attitudes; adoption/adaptation of new practices; physical infrastructure investments; and enacting policies to provide enabling environment and ensure sustainability of efforts.

4. A rich collection of knowledge systems and technological options are available to support CCA and DRR efforts. However, there is also a need to document, validate, and package local knowledge and practices, including socioeconomic and cultural aspects, for promotion and upscaling as appropriate, along with the sciencebased technologies.

5. Due attention should be given to most vulnerable or degraded (agro) ecosystems; most vulnerable or marginalised populations groups (women, children, indigenous peoples); and even to neglected but ecologically and nutritionally important crops.

6. It is important to counterpart with the local communities and engage them in participatory processes - from needs analysis, implementation, up to monitoring and evaluation. This gives local people a sense of ownership for project initiatives as well as helps ensure sustainable and long-term changes.

To sufficiently meet the huge challenges in ensuring food/nutritional security and environmental sustainability, the following are additional recommendations:

1. Continue strengthening collaborations in R\&D, education, and community development efforts across public and private agencies - covering local, national, regional, and global scales.

2. Mainstream science and technology including good local practices in local and national governance systems as this will help ensure sustainability.

3. Strengthen extension programmes and knowledge transfer of research institutions including exchange between and among agencies working on climate change. This can be done through existing extension systems and networks; collaborative projects and activities; various fora such as training workshops and conferences; including online resources such as SEARCA's KC3.

AOA2012-08NSY-LANSIGAN

\section{PROJECT TITLE}

International Conference on Climate
Change Impacts and Adaption for Food
and Environmental Security, 21-22
November 2012, Los Baños, Laguna,
Philippines

\section{COUNTRIES INVOLVED}

Southeast Asian countries

\section{DURATION}

1 year
APN FUNDING

US\$10,000

\section{PROJECT LEADER}

Prof. Felino LANSIGAN

International Conference Committee University of the Philippines Los Banos College, Laguna 4031, Philippines

Tel: +63495362381

Email: fplansigan@yahoo.com

Website: http://icciafes.searcabackup.org 


\section{Science-Policy Dialogue on Challenges of Global Environmental Change in Southeast Asia}

Linda Anne Stevenson', Jariya Boonjawat, Hassan Virji, Marwaan Macan-Markar, Xiaojun Deng

'Corresponding Author

Asia-Pacific Network for Global Change Research, Kobe, Japan

lastevenson@apn-gcr.org

ABSTRACT: The Science-Policy Dialogue on Challenges of Global Environmental Change in Southeast Asia was held in Bangkok, Thailand, 19-21 July 2012, hosted by the Southeast Asia START Regional Center with support from APN and START. It was designed to provide scientific input to policy decision-making and promote science-policy interaction through facilitated discussions and participatory game sessions on communicating recent advances in scientific knowledge pertaining to ecosystem services; climate change vulnerability and impacts; disaster risk reduction and management; and strategies for adaptation. Participants considered implications for decision- and policy-making communities, informed them of potential actions to reduce vulnerability and promote adaptation, and promoted tools for decision-making under uncertainty and multiple stresses.

KEYWORDS: science-policy interaction, adaptation strategies, ecosystem services, vulnerability and impacts, disaster risk reduction 
Prof. Graeme

Pearman provides

key insights to

the science-policy conundrum.

\section{Background}

In light of the outcomes of UNFCCC COP17 in Durban (December 2011), the Planet under Pressure Conference in London (March 2012) and the Rio+20 Conference in Rio de Janeiro (June 2012), the APN-START Science-Policy Dialogue (SPD) on Challenges of Global Environmental Change in Southeast Asia was held to promote informed decision-making on actions to reduce global environmental change vulnerability and promote climate adaptation strategies.

The SPD, held in Bangkok, Thailand, 19-21 July 2012, was attended by 98 scientists and mid-level policy makers from Southeast Asia, including invited experts on global change science, senior policy makers in the region, and observers from Temperate East Asia and South Asia.

Hosted by the Southeast Asia START Regional Center with support from APN and START (through a grant from USGCRP), the three-day dialogue confirmed the need to foster stronger partnerships between the scientific and policy communities and the private sector to help shape adaptation strategies. Such sustained partnerships would benefit from a range of short- and long-term science-based policy options.

\section{Summary}

The SPD was designed to provide scientific input to policy decision-making and promote science-policy interaction through facilitated discussions and participatory game sessions on communicating recent advances in scientific knowledge pertaining to ecosystem services; climate change vulnerability and impacts; disaster risk reduction and management; and strategies for adaptation.

Participants considered implications for the decision- and policy-making communities, informed them of potential actions to reduce vulnerability and promote adaptation, and promoted tools for decisionmaking under uncertainty and multiple stresses. In a follow-up review, participants and organisers discussed the need for sustaining the momentum of these kinds of dialogues as well as other science-policy interactions in the future.

The present article attempts to present a summary of the discussions taken place during the SPD, structured in a way that it responds to the five broad questions set forth at the opening session of the event (Fuchs, 2012).

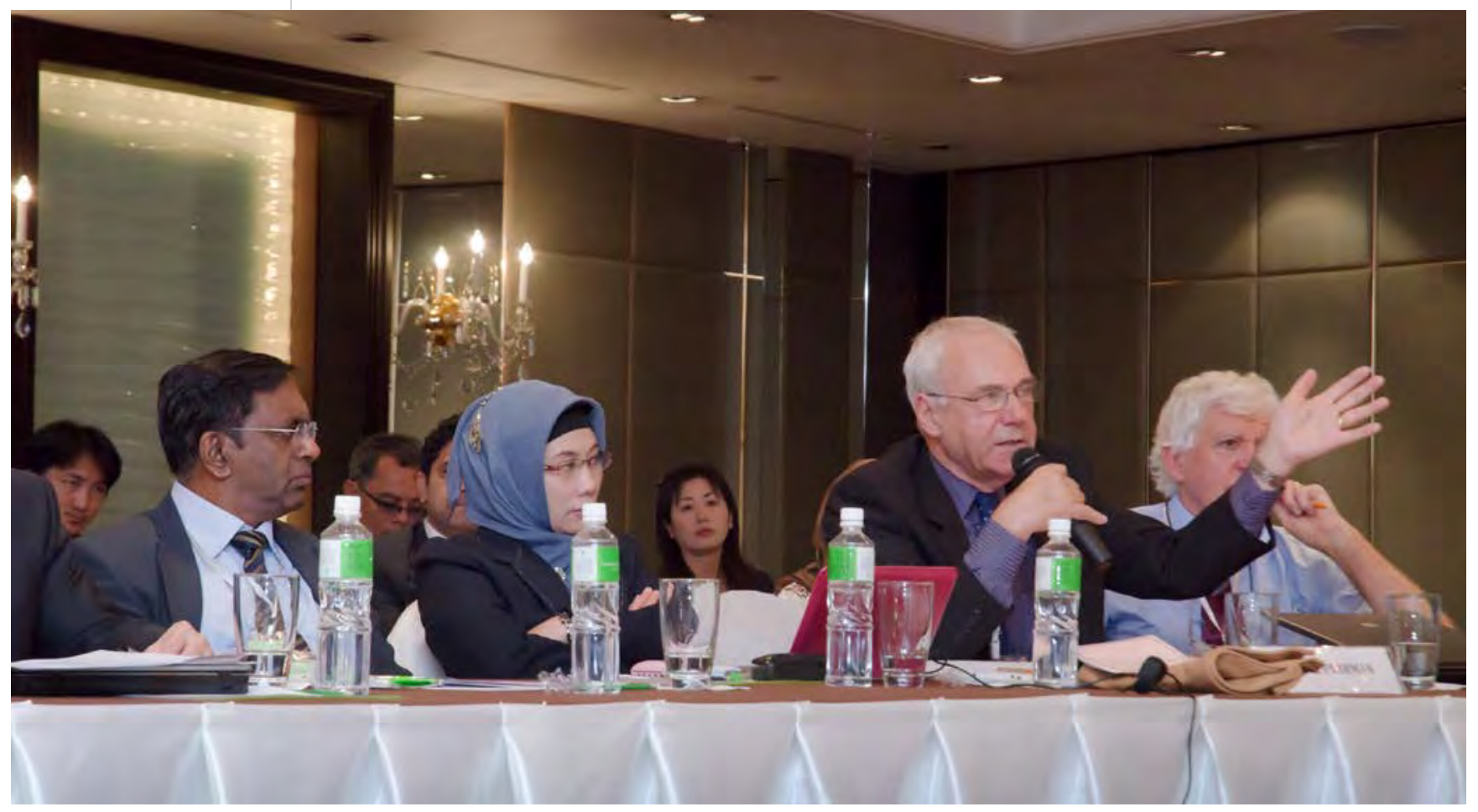




\section{How Adequate is the Knowledge Base?}

While scientists are still grappling with the challenge of modelling for extreme event conditions, the world is moving into climate regimes that have no comparisons with the past. Hence, the past may not be the guide for countries as they tackle climate uncertainties and changing risks. This will require new strategies and discussions to deal with uncertainty.

Local community needs have to be factored in by both the science and policy communities, so research can offer answers to what concerns these local communities have in this time of global change.

There is a need for more research and development to understand extreme weather patterns.

Knowledge production needs to be broadened, going beyond scientists and policy makers to include other actors who matter. This multi-stakeholder production of knowledge and dialogue should include the private sector, local communities, non-governmental organisations, and civil society organisations.

\section{To What Extent do Actors Make Use of the Knowledge?}

There is still a gap about what role science has and where it can fit in to implement community-based adaptation.

Knowledge generated by scientists is often challenged by those with strong views about local knowledge, such is the case in land use and forestry-related issues in Thailand. Therefore, there is a tendency by local communities to dismiss new, scientific knowledge as "not being from this place."

There is concern about the gap between good technical data and using information for action-oriented programmes. Problems in producing action-relevant information, how data is gathered, how it is managed and the quality of that data exist. This matters since adaptation at both metropolitan and community levels give rise to politically-profound issues.

Countries need to draw lessons from natural disasters and rebuild their warning systems, disaster management systems, examine reservoir operations, improve capacity of flood retention areas and rethink land-use control policies.

\section{What Barriers and Failures Limit the Transfer of Knowledge?}

Barriers exist when scientific information is needed to formulate policies that have to be implemented.
Scientists need to consider short- and long-term options and need to give policy makers information that offers solutions. They also need to realise that the people in the government who make decisions about what policies to implement are held accountable to those decisions.

Scientists face difficulties when policy makers ask for scenarios that are certain and can be implemented, when research shows that there is uncertainty about how the future will unfold.

Scientists also face difficulties conveying information to ministers and policy makers because of communication gaps - scientific information is not easily understood by the policy community - and the fact that government officials tend to move to other positions where their portfolio may no longer require scientific information on global and climate change.

Problems within government systems were highlighted as hurdles. This arose from the prevailing order of "ministerial silos"; where, say, the ministries of water, environment and agriculture are protective of their respective turf and do not meet. Cross-ministerial thinking is encouraged, focusing on issues across sectors, which requires re-imagining how countries are governed and systems of administration in these countries. For example, a watershed as a basic unit of governance could offer an option for physical integration across policy sectors and political boundaries.

Many countries in Southeast Asia place food security as their first priority, yet they also need energy for development. So they face questions about how best to manage their water supply between the needs of agriculture and hydropower. This is an example of where science can help by offering answers.

\section{How do Institutions Shape the Science-Policy Interface?}

The main benefit of a dialogue comes from human interaction. There is a need to test one's ideas with others who face similar situations and have an exchange about what does and doesn't work.

ASEAN already has the ASEAN Charter, which could help in the region by allowing countries to work across the board with local communities. International organisations such as the United Nations Environment Programme (UNEP), the Asia-Pacific Adaptation Network (APAN), among others, have information on good adaptation practices that is open to the public.

The Asian Development Bank (ADB) is working to develop private-public partnerships, such as the green business venture in the Pacific Islands. In addition, the 
ADB has shifted focus from having only an agriculture policy (seen as too narrow) to a broader policy that addresses food security. In supporting such programmes, the ADB does not just lend money, but it also helps to develop smarter strategies.

\section{How Can the Science-Policy Interface Best be Improved?}

In the area of implementing programmes suggested by scientists, participants emphasised the importance of having local champions in the policy sector who understand the issue and can help implement programmes that matter.

In order to get policy makers engaged and understand the methodology used, scientists need to convince them through case studies demonstrating meaningful actions. Another suggestion to improve science-policy interface was for scientists to produce information that can lead to action.

Social media, such as Facebook, needs to be incorporated as part of advocacy and awareness raising efforts to get community support. Social media played a major role in disseminating information to the public during the 2011 floods in Thailand.

In trying to build programmes for sustainable ecosystem services, an equally important component is to build trust among all those involved. One solution is to combine good local knowledge with scientific knowledge to shape policies.

A science-policy interface has to be actively managed, since governance is about who controls what and how such control is exerted. In this context, science should be brought to local levels to contribute critical inputs, so decision makers have a diversity of information to choose from to shape policies at the local level.

The SPD needs to be aware of new trends in universities, such as in Malaysia where universities are moving into action-oriented research.

Management of risks in urban setting requires innovative urban planning. Malaysia's SMART Tunnel, which gives way from motor traffic usage to a water transfer channel following periods of heavy precipitation, serves as a good example.

Partnerships between the science and policy communities need to be looked at with the aim of identifying what works and what doesn't.

There is a need to expand partnerships to other sectors not only the science community. The development community is one to reach out to.

\section{References}

Fuchs, R. (2012, July 19). Science-Policy Dialogue on Challenges of Global Change in Southeast Asia, Context and Objectives. Presented at the Science-Policy Dialogue on Challenges of Global Environmental Change in Southeast Asia, Bangkok, Thailand. Retrieved from http://www. cckm.or.th/drupal/2012/07/202

\section{PROJECT TITLE}

\section{Science-Policy Dialogue on Challenges of Global Environmental Change in Southeast Asia}

\section{COUNTRIES INVOLVED}

Southeast Asian countries

\section{DURATION}

1 year

\section{APN FUNDING}

\section{LEAD INSTITUTIONS}

Southeast Asia START Regional Center (SEA START RC), START International, Asia-Pacific Network for Global Change Research (APN)

\section{FULL ADDRESS}

SEA START RC

Chulalongkorn University, 5th Floor, Chulawich1

Building

Henri Dunant Road, Bangkok 10330, THAILAND

Website: http://www.start.or.th 


\title{
Building Resilience with Common Capital
}

\author{
Eduardo Brondizio, Anantha Duraiappha, Nimal Gunatilleke, Shizuka Hashimoto, Srikantha Herath, Gamini Hitinay- \\ ake, Yukihiro Imanari, Hiroaki Ishida, Nicolas Kosoy, Asumo Kuroda, Patrick O'Farrell, Anne-Hélène Prieur-richard, \\ Osamu Saito', Suneetha Subramanian, Akio Takemoto, Kazuhiko Takemoto, Kazuhiko Takeuchi, Suchada Wattana \\ 'Corresponding author \\ United Nations Institute-Institute for Sustainability and Peace \\ Email: saito@unu.edu
}

ABSTRACT: In Japan, Satoyama landscapes have been rapidly declining due to various factors including increased rural-urban migration, rapidly aging population, depopulation, land-use conversion and the abandonment of traditional agricultural cultivation. The loss of collective management of Satoyama and Satoumi landscapes may be termed a loss of the "commons." Critical to the success of a more integrated and holistic approach to ecosystems management is the creation of a new "commons," understood both as a system of co-management of ecosystem services and biodiversity within private, communal, and public land; and as a single system to produce a bundle of ecosystem services that exhibit both public and private properties, and for direct and indirect use by society with a long-term perspective. The new "commons" could provide the basis for sustainable development in both developing and developed countries. The series of workshops explored ways and means of enhancing resilience of communities to climate and ecosystems change by identifying new governance systems overseeing the management of the New Commons, supply of ecosystem services and enhancement of socio-ecological resilience against climate and ecosystem changes in an efficient and equitable manner across a range of stakeholders.

KEYWORDS: satoyama, ecosystem services, governance, mismatch, resilience 


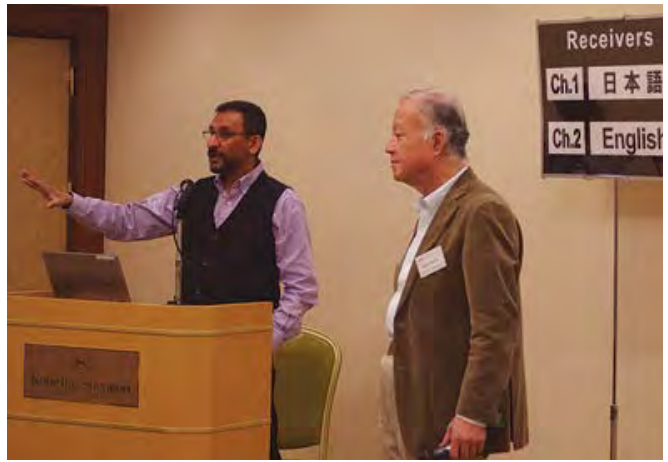

\section{Introduction}

Satoyama is a Japanese term for traditional rural production landscapes. These traditional landscapes, however, can be characterised as a mosaic of different ecosystem types - secondary forests, farmlands, irrigation ponds and grasslands - along with human settlements, which have been managed to produce bundles of ecosystem services for human well-being. Satoyama, found largely in rural and peri-urban areas of Japan, is a way of life. In other words, it is a classical illustration of the symbiotic interaction between ecosystems and humans.

The Japan Satoyama-Satoumi Assessment (JSSA, 2010; Duraiappah et al., 2012) shows how Satoyama landscapes have been rapidly declining due to various factors including increased rural-urban migration, the rapidly aging population, depopulation, land-use conversion and the abandonment of traditional agricultural cultivation. If this trend continues, vital services provided by Satoyama will be adversely affected causing changes in human wellbeing across a range of stakeholders.

There is no doubt that short-term increases in certain aspects of human wellbeing have been accompanied by degradation of ecosystem services, which, over the long term, may have negative consequences on human wellbeing. Two factors have been critical in these winlose scenarios between human wellbeing and satoyama ecosystems. First, with the uprooting of the Japanese population in post-war years as rural populations declined and urban ones swelled, there is collective loss of connection to one's landscape.

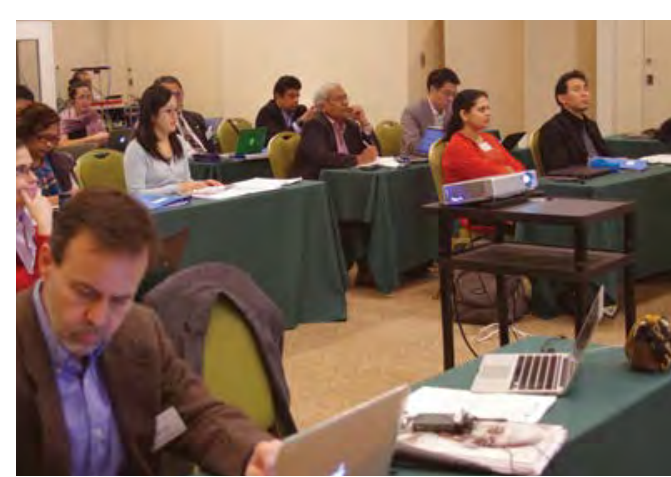

Wherein traditionally, those who worked the land and the waters assumed collective responsibility for maintaining and protecting them, in a rapidly urbanised and industrialised Japan, this sense of obligation to one's surroundings has been quickly lost. Thus, it becomes possible to pursue economic development that produces short-term benefits to human wellbeing, while simultaneously degrading the ecosystems necessary to sustain wellbeing over the long haul.

This loss of collective management of Satoyama and Satoumi landscapes may be termed a loss of the "commons." Critical to the success of a more integrated and holistic approach to ecosystems management is the creation of a new "commons," understood both as a system of co-management of ecosystem services and biodiversity within private, communal, and public land, and as a single system to produce a bundle of ecosystem services that exhibit both public and private properties, and for direct and indirect use by society within a long-term perspective. The new "commons" could provide the basis for sustainable development in both developing and developed countries.

The essence of landscapes such as Satoyama is that coexistence of human society and the natural environment is achieved through sustainable management of a mosaic composition of different ecosystem types each operating under a variety of tenure regimes. This essence has the quality of contributing to the maintenance of biodiversity cultivated by human intervention and management of secondary nature.

Learning from this essence of the traditional human and nature relationships, we should focus on establishing new governance mechanisms that can manage 
private, public and communal lands as a single integrated system. This approach is similar in some ways to the already existing concepts of agroforestry but still falls short of addressing the full range of ecosystem services that are provided and the missing markets for some of the public services that are offered by Satoyama-type landscapes.

The series of workshops explored ways and means of enhancing resilience of communities to climate and ecosystems change by identifying new governance systems overseeing the management of the New Commons, supply of ecosystem services and enhancement of socioecological resilience against climate and ecosystem changes in an efficient and equitable manner across a range of stakeholders.

\section{Methodology}

A series of three 3-day workshops were organised. A group of experts attended the workshops to ensure continuity of the process and the development of a New Commons framework and to showcase studies in Japan and other countries in the Asia-Pacific that have Satoyama-type landscapes. For each workshop, around 15 core participants were invited. The first workshop was held in Tokyo, Japan (23-25 January 2012), the second in Colombo, Sri Lanka (28-29 May 2012), and the final workshop was in Kobe, Japan (3-5 December 2012). For the second and third workshops, participants visited Satoyama districts. On the third workshop field trip, they visited Kurokawa in Kawanishi City, Hyogo Prefecture and learned that Satoyama landscapes have been conserved through sustainable use of natural resources such as the production of kiku-zumi charcoal.

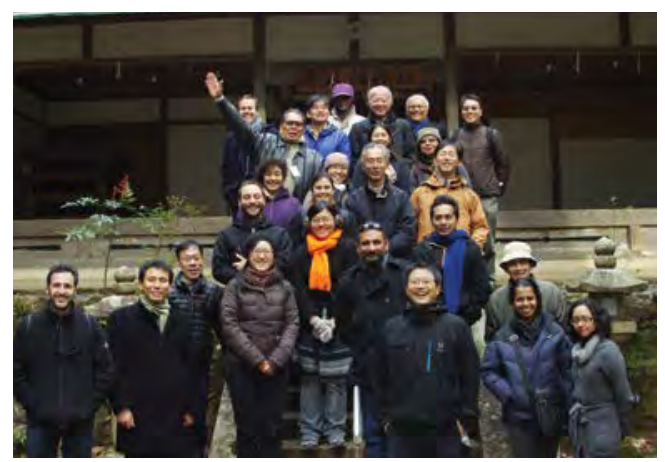

\section{Results}

Our point of departure is that human wellbeing is increasingly associated with the stability and functioning of local environments as much as it is with regional and global ecological processes. We recognise ecological processes and functions responsible for the flow of services as critical natural capital (CNC) and consider them as "new commons" requiring specific institutional arrangements, which recognise the connectivity within which local and regional economies and wellbeing are embedded. In this article, we present a conceptual framework that articulates the linkages between socioeconomic processes related to human wellbeing and of the provision of multiple ecosystem services - called "bundle of ecosystem services" - at multiple scales. The end goal is to design a framework to manage ecosystems supporting these bundles of ecosystem services ensuring overall CNC is retained. We pay particular attention to the intrinsic and cross-scale interdependency of society on CNC and the role of (bundles of) institutional arrangements, at different levels, mediating these relationships.

In the project, three key mismatches relating to ecology, institutions and values were illustrated and we showed how these mismatches have perpetuated the decline of ecosystem services and wellbeing at different scales. The project provides a conceptual framework for understanding and managing these identified mismatches and lays out the key components underlying the concept of the New Commons and the main interlinkages and relationships both within and across scales to address the three mismatches. These results will be published

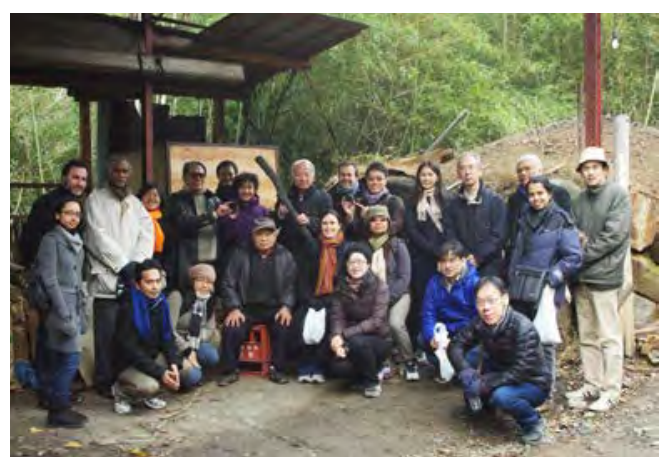




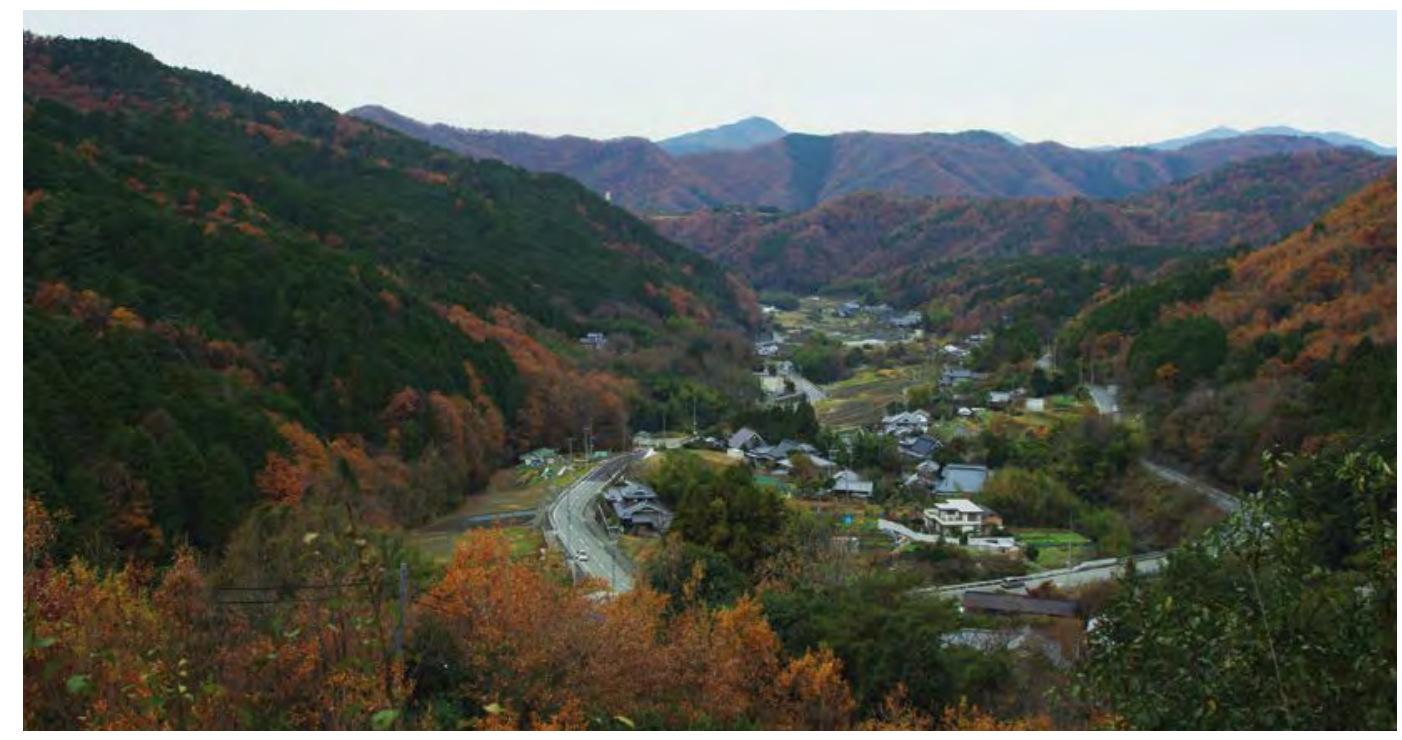

in detail in peer-reviewed literature and some articles are currently being drafted by the core group.

\section{References}

Japan Satoyama-Satoumi Assessment (2010). Satoyama-satoumi ecosystems and human well-being: Socioecological production landscapes of Japan - Summary for decision makers. Tech. rep., United Nations University, Tokyo. Retrieved from http://www.ias.unu.edu/sub_page. aspx?catID $=111 \& d d I I D=1418$

Duraiappah,A.K., Nakamura,K.,Takeuchi,K., Watanabe, M., \& Nishi, M. (Eds.). (2012). Satoyama-satoumi ecosystems and human well-being: Socio-ecological production landscapes of Japan. Tokyo: United Nations University Press. Retrieved from http://unu.edu/publications/books/ satoyama-satoumi-ecosystems-andhuman-well-being-socio-ecologicalproduction-landscapes-of-japan-2.html

\section{Acknowledgments}

This project was conducted as a Hyogo Activity of APN. The project team extends its sincere thanks to Hyogo Prefectural Government of Japan for supporting the project.

\section{AOA2011-02NSY-NEWCOMMONS}

\section{PROJECT TITLE}

\section{Building Resilience with Common \\ Capital - Managing Shared Resources: Meeting the Challenges of a Rapidly Modernising World under Climate and Ecosystems Change}

\section{COUNTRIES INVOLVED}

France, Germany, Japan, Indonesia, USA, Cambodia, Canada, South Africa, Sri Lanka, Thailand

\section{DURATION}

$$
2 \text { years }
$$

\section{APN FUNDING}

US\$ 50,000

\section{LEAD INSTITUTIONS}

United Nations University (UNU), International Human Dimensions Programme (IHDP), DIVERSITAS, Asia-Pacific Network for Global Change Research (APN)

APN Secretariat, East Building, 4F 1-5-2

Wakinohama Kaigan Dori Chuo-ku, Kobe 651-0073 JAPAN

\section{Tel: +81 782308017}

Email: info@apn-gcr.org

Website: www.apn-gcr.org 


\title{
APN-IGES-Hyogo Symposium on Low Carbon Society in Asia through Dissemination of Renewable Energy Technology
}

\author{
Masayuki Ishizu', Akio Takemoto \\ 'Corresponding Author \\ Asia-Pacific Network for Global Change Research \\ Email:mishizu@apn-gcr.org
}

ABSTRACT: Renewable energy technologies are innovative and promising technologies to achieve low carbon development both in developed and developing countries in Asia. Various types of renewables such as solar, wind power and biomass energy are being or will be disseminated in Asian countries through policy arrangement such as regulatory schemes, target setting and economic incentives including Feed-in-Tariff. The Asia-Pacific Network for Global Change Research (APN), Institute for Global Environmental Strategies (IGES), and Hyogo Prefecture organised a "Symposium on Low Carbon Society in Asia through Dissemination of Renewable Energy Technology" in Kobe, Japan in order to provide the latest information on renewable energy technologies that have been introduced in Japan and Asian developing countries, to the public; and to exchange views among participants on gaps, lessons and solutions to achieve low carbon societies.

KEYWORDS: renewable energy, low carbon, technology, solar, wind power, biomass

\section{HIGHLIGHTS}

» The Governor of Hyogo Prefecture, Toshizo Ido, made the opening remarks.

» Keynote Speech: "Practical use of renewable energy, and a fixed-price acquisition system” by Dr. Kasuhiro Ueta, Professor, Graduate School of Global Environmental Studies \& Graduate School of Economics, Kyoto University

» The renewable energy situation of Thailand and Malaysia was introduced by guest speakers.

» Good practices were introduced by private companies and Hyogo Prefectural Government. 


\section{Introduction}

All countries should work together towards low carbon development and green growth by enhancing mitigation action on climate change.

The Hyogo Prefectural Government of Japan, which hosts the APN Secretariat and is a major financial contributor to the APN, is keen on implementing mitigation measures at a local scale, including $\mathrm{CO}_{2}$ emission reduction in public and commercial sectors by way of regulatory, economic and informational measures to encourage energy-saving.

The Institute for Global Environmental Strategies, Kansai Research Centre (IGES/ KRC) is a Hyogo-based research institution which conducts research activities on "Business and Environment" including experimental studies on low carbon technology transfer in Asia.

The APN, IGES/KRC and Hyogo Prefecture can benefit from a communications event on low carbon development, which facilitates mutual understanding on the latest technological know-how, legal framework and lifestyle with regard to low carbon development. It was also important to hold such an event from the viewpoint of the redistribution of APN's outcomes to Hyogo Prefecture, which has supported the APN for more than 12 years.
In this regard, APN, IGES/KRC and Hyogo Prefecture organised a "Symposium on Low Carbon Society in Asia through Dissemination of Renewable Energy Technology" to provide the latest information on renewable energy technologies, introduced in Japan and Asian developing countries to the public, and to exchange views among participants on gaps, lessons and solutions to achieve a low carbon society in Asian countries.

\section{Results}

The Symposium was held on 18 February 2013 at ANA Crown Plaza Hotel, Kobe, Japan and attended by more than 250 participants. The agenda of the Symposium was as follows:

\section{3:30 Opening Remarks}

Toshizo Ido, Governor of Hyogo Prefecture

\section{3:40 Keynote Speech}

Practical use of renewable energy, and a fixed-price acquisition system

Professor, Dr. Kazuhiro Ueta, Professor, Graduate School of Global Environmental Studies \& Graduate School of Economics, Kyoto University

\section{4:10 Guest Speech 1}

Professor, Dr. Bundit Fungtammasan, Vice President for Research, King Mongkut's University of Technology Thonburi, Thailand

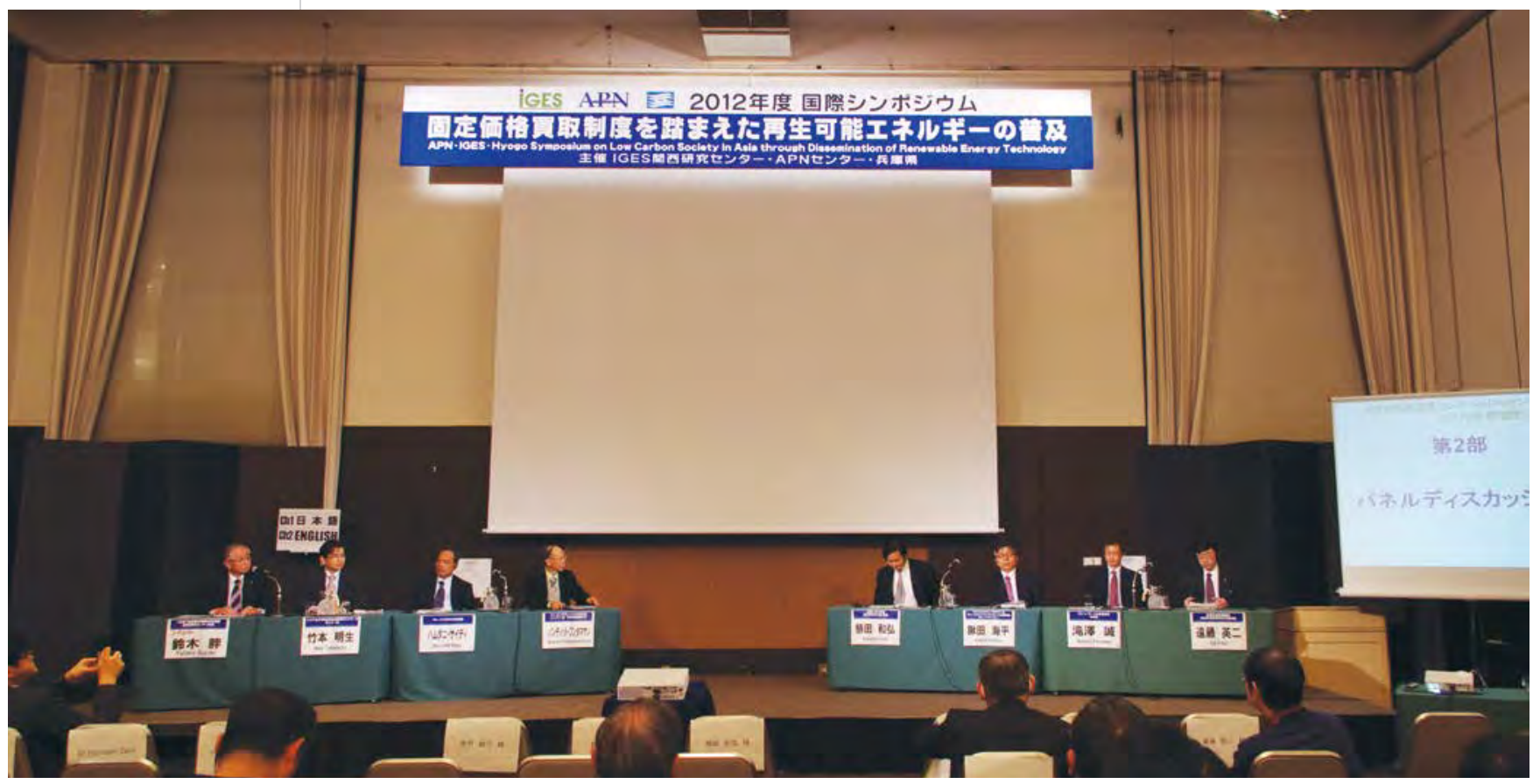



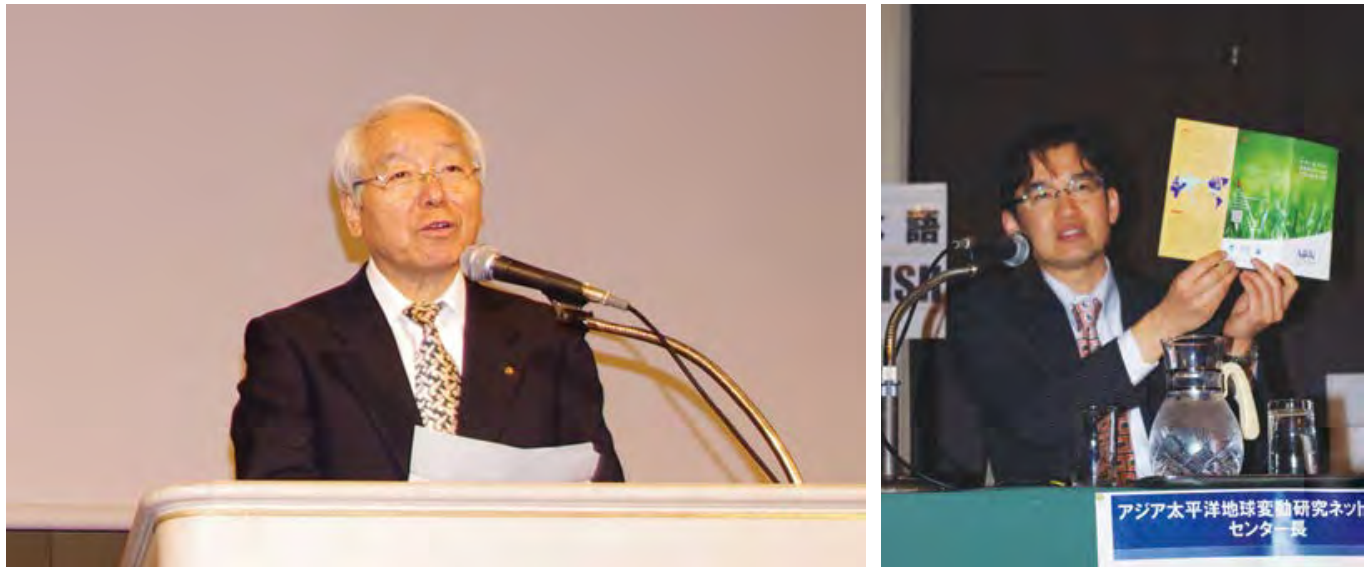

Hyogo Governor Ido and APN Director Akio Takemoto (right) during

\section{4:30 Guest Speech 2}

Professor, Dr. Hamdani Saidi, Professor, Director of UTM International Campus, Universiti Teknologi Malaysia

\section{5:00 Good Practices Presentation 1}

Practical use of the renewable energy by a storage battery system

Mr. Kaihei Kuwata, Group Manager, Panasonic Energy Company

15:20 Good practices Presentation 2

Introductory promotion of the photovoltaics of Hyogo Prefecture

Mr. Eiji Endo, Director, Global Warming Solutions Division, Hyogo Prefectural Government

\section{5:40 Good practices Presentation 3}

The woody biomass power generation system by forest unused material

Mr. Makoto Takizawa, Director, Green Thermal Co. Ltd.

\section{6:00 Panel Discussion}

Coordinator: Professor Yutaka Suzuki, Director-General, IGES Kansai Research Center

Panelist: Professor Ueta, Dr. Fungtammasan, Dr. Saidi, Mr. Kuwata, Mr. Endo, Mr. Takizawa, Akio Takemoto (APN Secretariat Director)

\section{7:30 Closing Remarks}

Professor Yutaka Suzuki, DirectorGeneral, IGES Kansai Research Center

After the opening remarks by Hyogo Governor Mr. Toshizo Ido, Professor Kazuhiro Ueta of Kyoto University made a keynote speech. He introduced the fixed price acquisition system for renewable energy power generation which was recently established in Japan. He highlighted that diffusion of renewable energy is highly affected by new energy policies, including that of nuclear power generation. The characteristics of renewable energy, such as wind power generation and photovoltaics depend on local resources. He stressed that renewable energy has the advantage of having various co-benefits, such as fostering industries and revitalising regional economies.

Following the keynote speech, Professor Bundit Fungtammasan, King Mongkut's University of Technology Thonburi, Thailand, and Professor Hamdani Saidi, Universiti Teknologi, Malaysia delivered keynote messages and an overview on renewable energy technology and policy in their own countries. Professor Fungtammasan mentioned that $70 \%$ of electric power generation in Thailand is from natural gas, $20 \%$ from coal, $5 \%$ from hydraulic power and renewable energy $2 \%$. He stressed that Thailand imports a large amount of resources, which accounts for $47 \%$ of its total energy consumption; therefore, Thailand is committed to promoting renewable energy. Professor Saidi mentioned that Malaysia depends on fossil fuels too much, and the percentage of renewable energy is currently about $1 \%$. They have made a target to increase this to $10 \%$ in the future.

After the guest speeches, there were presentations on good practices for deployment of renewable energy by Japanese experts. Mr. Kaihei Kuwata, Panasonic Energy Company, introduced the utilisation of renewable energy through a storage battery system. He said that 


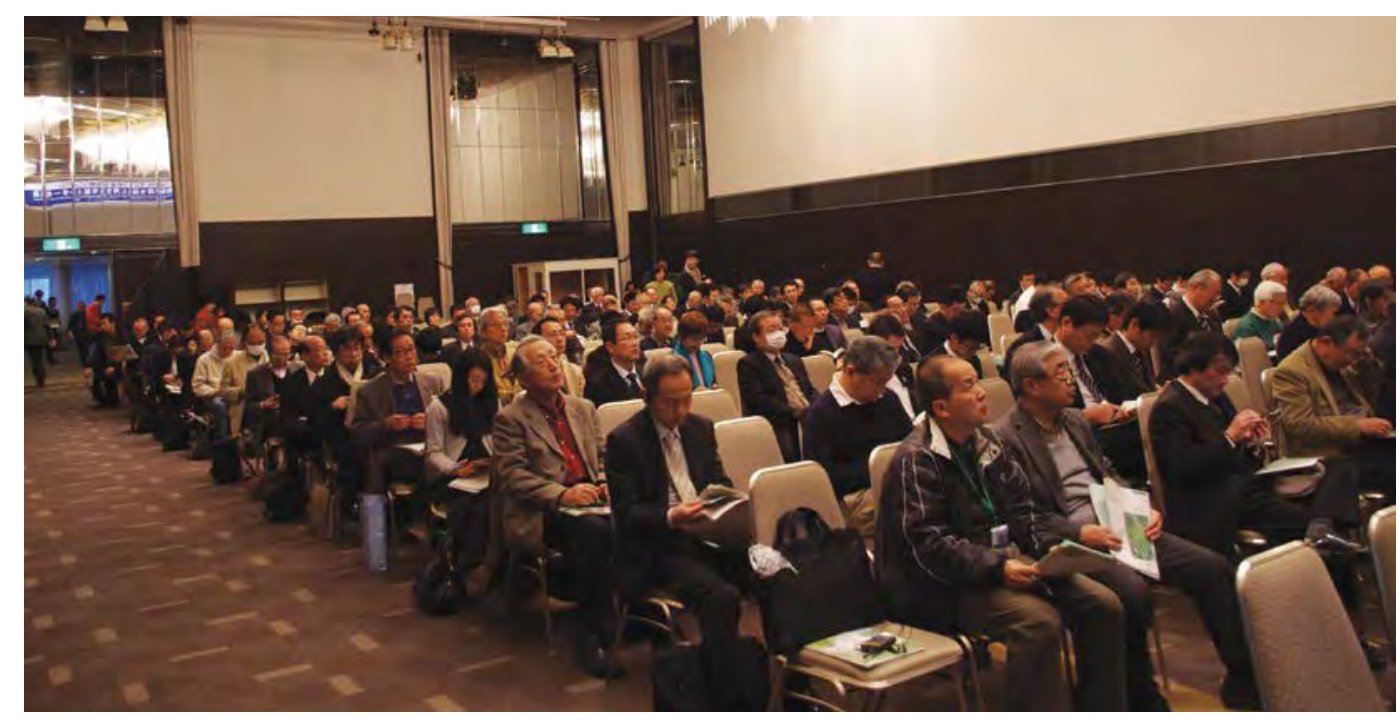

Panasonic has made a storage battery system using lithium-ion for small, medium and large size systems and this will contribute to promoting smart grids in the future.

Mr. Eiji Endo, Hyogo Prefecture, introduced the various measures taken to promote renewable energy by Hyogo Prefectural Government. These measures include low interest rate loans for the public and businesses, introduction of photovoltaic power generation into prefectural facilities, provision of information via websites and research activities.

Mr. Makoto Takizawa, Green Thermal Co. Ltd., introduced a biomass power generation system using unused and abundant forestry resources in local areas. He stressed that this biomass power generation system can produce electricity without carbon emissions and transportation costs because the power plant can be installed in the vicinity of a mountain. He expects that this system will revitalise the forest industry in local areas.

In panel discussions, adding to the speakers at previous sessions, Dr. Akio Takemoto, APN Secretariat, joined the session. Professor Yutaka Suzuki, Director-General, IGES/ KRC moderated the discussion between participants and panellists.

The symposium was a successful event. Participants shared and discussed among them the latest information on policy frameworks, technologies and systems on renewable energy and the barriers and solutions for dissemination of renewable energy through keynote speeches, good practices and panel discussions.

AOA2012-NSY09-APN/IGES/HYOGO

\section{PROJECT TITLE}

\section{APN-IGES-Hyogo Symposium on Low Carbon Society in Asia through Dissemination of Renewable Energy Technology}

\section{COUNTRIES INVOLVED}

Japan, Thailand, Malaysia

\section{DURATION}

1 year

\section{APN FUNDING}

US\$ 40,000

\section{LEAD INSTITUTION}

APN Secretariat, East Building, 4F 1-5-2 Wakinohama Kaigan Dori Chuo-ku, Kobe 651-0073 JAPAN

Tel: +81782308017

Email:info@apn-gcr.org

Website: www.apn-gcr.org 
The Scientific Planning Group (SPG) recommends the scientific programme and proposals for funding priority to the Inter-Governmental Meeting (IGM); works with the Steering Committee and the Secretariat in undertaking scientific activities; and interacts on the APN's behalf with other international research programmes on global environmental change. The SPG Members interact with the national Focal Points of their respective countries, the Secretariat, and the national and global change communities.

\author{
AUSTRALIA \\ Vacant \\ BANGLADESH \\ Md. Giashuddin MIAH \\ giash1960@gmail.com

\section{BHUTAN \\ Peldon TSHERING \\ Peldon@nec.gov.bt}

\section{CAMBODIA} \\ Veasna KUM \\ veasna_kum@yahoo.com

\section{CHINA \\ Wenjie DONG \\ dongwj@bnu.edu.cn}

FIJI

Vacant

INDIA

B.N. GOSWAMI

goswami@tropmet.res.in

INDONESIA

Erna Sri ADININGSIH

ernasri@lapan.go.id;

ernasri@yahoo.com

\author{
JAPAN \\ Kensuke FUKUSHI \\ fukushi@ir3s.u-tokyo.ac.jp
}

LAO PEOPLE'S DEMOCRATIC

REPUBLIC

Bounyaseng SENGKHAMMY

bounyaseng@gmail.com

MALAYSIA

Subramaniam MOTEN

subra@met.gov.my

MONGOLIA

Tsogtbaatar JAMSRAN

tsogtbaatarj@magicnet.mn;

geoeco@magicnet.mn

NEPAL

Madan Lall SHRESTHA

madanls1949@gmail.com

\section{NEW ZEALAND}

Andy REISINGER

andy.reisinger@nzagrc.org.nz

PAKISTAN

Amir MUHAMMED

amir.muhammed@nu.edu.pk; amir.muhammed@gmail.com
PHILIPPINES

Marcial C. AMARO Jr. erdb@denr.gov.ph; amaromarsjr@yahoo.com

REPUBLIC OF KOREA

Soojeong MYEONG

sjmyeong@kei.re.kr

RUSSIAN FEDERATION

Alexander STERIN

sterin@meteo.ru

\section{SRI LANKA}

S. H. KARIYAWASAM

meteo1@sltnet.Ik

THAILAND

Jariya BOONJAWAT

jariya@start.or.th

UNITED STATES OF AMERICA

Luis M. TUPAS

Itupas@nifa.usda.gov

\section{VIET NAM}

Kim Chi NGO

chikimngo2@yahoo.com;

chikimngo2008@gmail.com

\section{Invited Experts to Scientific Planning Group}

\section{AILIKUN}

Director, International Program Office of Monsoon

Asia Integrated Regional Study (MAIRS)

aili@mairs-essp.org

\section{Congbin FU}

Director, Temperate East Asia Regional Committee for START

fcb@tea.ac.cn

Lance Clive HEATH

Project and Business Development Manager,

Climate Change Institute (CCl), Australian National

University

lance.heath@anu.edu.au
Kanayathu Chacko KOSHY

Professor, Centre for Global Sustainability Studies, Universiti Sains Malaysia

kanayathu.koshy@gmail.com

Chao Han LIU

Chairman, Southeast Asia Regional Committee for START

chliu@cc.ncu.edu.tw 


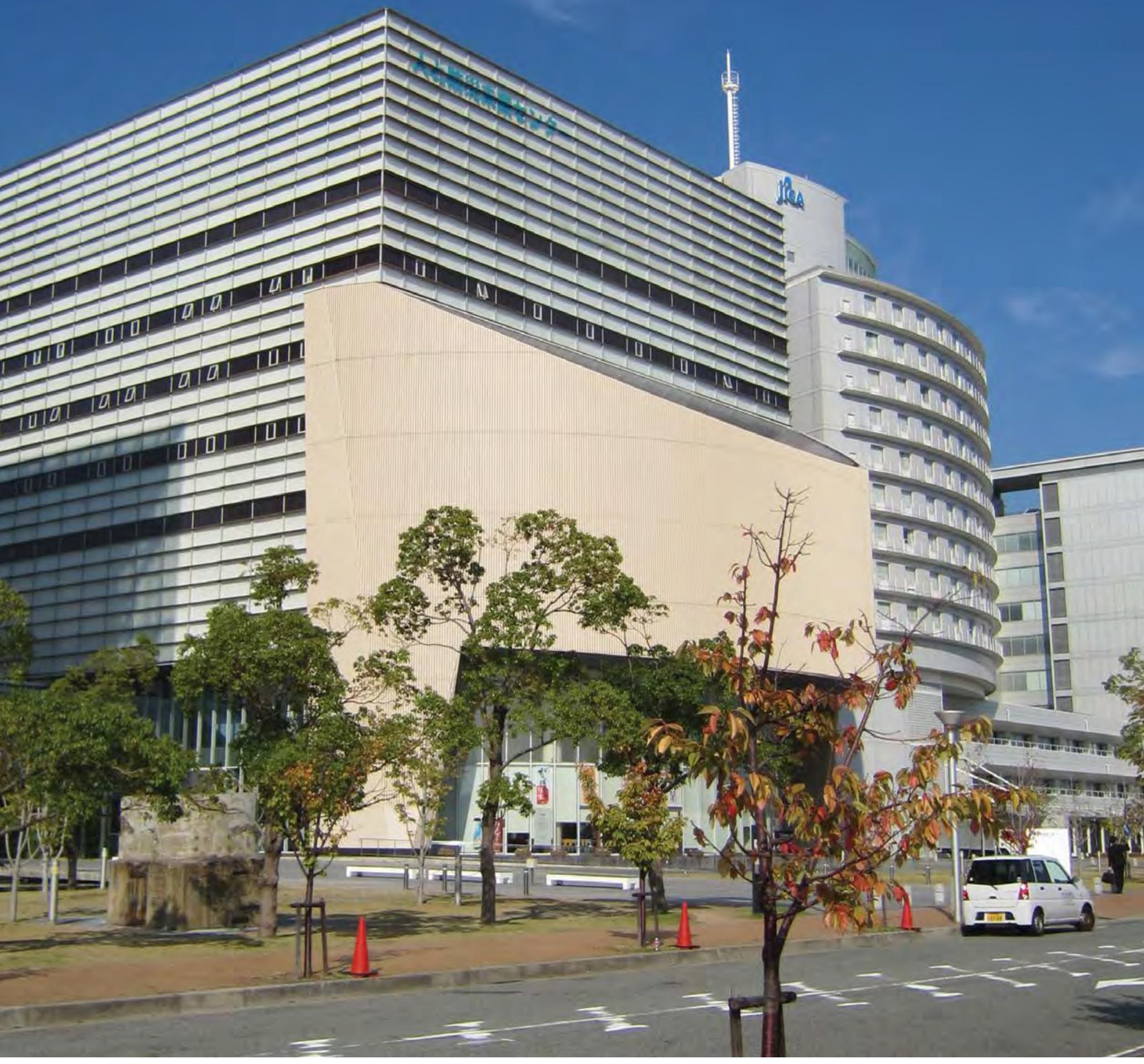

ADT

APN Secretariat

East Building, 4F

1-5-2 Wakinohama Kaigan Dori Chuo-ku, Kobe 651-0073 JAPAN
Tel: +8178230 8017

Fax: +81782308018

Email: info@apn-gcr.org

Website: www.apn-gcr.org 